Published in "Nature Reviews Molecular Cell Biology 9: 162-176, 2008"

which should be cited to refer to this work.

\title{
Lipid signalling in disease
}

\author{
Matthias P. Wymann* and Roger Schneiter \\ Abstract | Signalling lipids such as eicosanoids, phosphoinositides, sphingolipids and fatty \\ acids control important cellular processes, including cell proliferation, apoptosis, metabolism \\ and migration. Extracellular signals from cytokines, growth factors and nutrients control the \\ activity of a key set of lipid-modifying enzymes: phospholipases, prostaglandin synthase, \\ 5-lipoxygenase, phosphoinositide 3-kinase, sphingosine kinase and sphingomyelinase. \\ These enzymes and their downstream targets constitute a complex lipid signalling network \\ with multiple nodes of interaction and cross-regulation. Imbalances in this network \\ contribute to the pathogenesis of human disease. Although the function of a particular \\ signalling lipid is traditionally studied in isolation, this review attempts a more integrated \\ overview of the key role of these signalling lipids in inflammation, cancer and metabolic \\ disease, and discusses emerging strategies for therapeutic intervention.
}

Lipids have long since been recognized as signalling molecules that have the capacity to trigger profound physiological responses. Slow-reacting substance of anaphylaxis (SRS-A), now known to belong to the group of cysteinyl leukotrienes, was identified as early as 1930 (REF. 1); at about the same time, the vasodilating actions of prostaglandins were described ${ }^{2}$. Subsequently, arachidonic acid was identified as the source of leukotrienes and prostaglandins (BOX 1), a discovery that has led to our current understanding of eicosanoid signalling ${ }^{3}$, and taught us that one and the same signalling lipid can provoke different cellular responses, depending on the precise cell type and underlying signalling network present in the target cell.

The study of the lipid components of cellular membranes, and in particular the turnover of phosphoinositides, culminated in the 1980s with the discovery that phosphatidylinositol-4,5-bisphosphate (PtdIns $\left.(4,5) \mathrm{P}_{2}\right)$ could be hydrolysed by phospholipase $\mathrm{C}$ (PLC) to diacylglycerol (DAG) and inositol-1,4,5-trisphosphate $\left(\operatorname{Ins}(1,4,5) \mathrm{P}_{3}\right)$. Both products were identified as second messengers that trigger the activation of protein kinase C (PKC; REF. 4) and the release of $\mathrm{Ca}^{2+}$ from internal stores, respectively. In parallel, inositol and phosphoinositide kinases have been identified; these enzymes generate a huge repertoire of soluble inositol polyphosphates and membrane polyphosphoinositide lipids. Phosphoinositide 3-kinase (PI3K), for example, which is regulated by cell-surface receptors, promotes the formation of phosphatidylinositol-3,4,5-trisphosphate $\left(\operatorname{PtdIns}(3,4,5) \mathrm{P}_{3}\right)$, a signalling lipid that modulates cell growth, proliferation and motility ${ }^{5,6}$. Interestingly, nature has used several possible variations of the inositol head group to create highly specific docking sites for lipid-binding proteins - effector proteins that trigger signalling cascades or enzymes that further modify these lipids (BOX 2; see the review by Lemmon in this issue). Phosphoinositides have, therefore, gained importance as localization tags that are involved in the organization of membrane-bound signalling complexes ${ }^{7}$.

Ceramides and sphingosines are lipids that have pro-apoptotic and antiproliferative actions ${ }^{8}$; when phosphorylated by lipid kinases, however, sphingosine is converted into sphingosine-1-phosphate (S1P), which promotes cell growth and proliferation by a still poorly understood intracellular action as well as by extracellular signalling through a set of different $C$ protein-coupled receptors (GPCRs) ${ }^{9-11}$ (BOX 3; see the review by Hannun and Obeid in this issue). Another lipid that is released from cells, lysophosphatidic acid (LPA), also functions in an autocrine and paracrine manner by binding to a family of GPCRs ${ }^{12,13}$. LPA, together with specific eicosanoids, can additionally modulate gene expression by binding to lipid-sensing transcription activators, such as the peroxisome proliferator-activated receptors (PPARs) $)^{14,15}$ (BOX 4).

Imbalances of these major lipid signalling pathways contribute to disease progression in chronic inflammation, autoimmunity, allergy, cancer, atherosclerosis, hypertension, heart hypertrophy, metabolic and degenerative diseases, among others (FIG. 1). Owing to their complexity, these pathways are mostly studied and reviewed in isolation. However, many of these signalling lipids, their modifying enzymes and downstream targets 


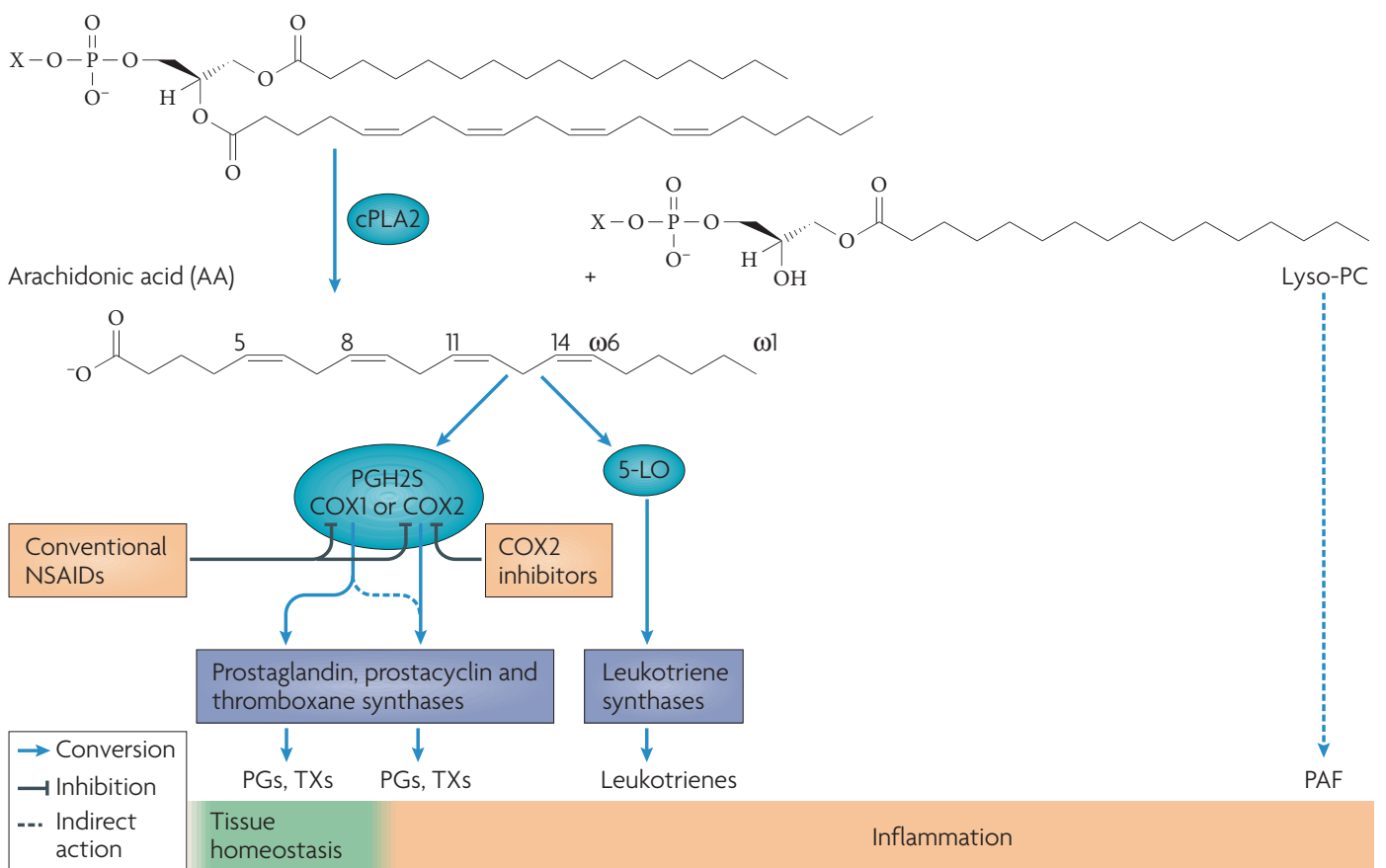

The production of eicosanoids is initiated by the release of C20-polyunsaturated fatty acids, such as arachidonic acid (AA, C20:4), from phospholipids (X stands for a phospholipid headgroup; see figure) or diacylglycerol (not shown; see BOX 2). This hydrolysis is catalysed by cytosolic phospholipase A2 (cPLA2). $\mathrm{Ca}^{2+}$-induced cPLA2 lipase action is the ratelimiting step in eicosanoid formation, and cells lacking cPLA2 are generally devoid of eicosanoids. Liberated fatty acids are then stereospecifically oxygenated either through the cyclic prostaglandin synthase pathway (prostaglandin $\mathrm{H} 2$ synthase ( $\mathrm{PGH} 2 \mathrm{~S}$ ), including cyclooxygenase (COX) activity) or through the linear lipoxygenase-dependent pathway (5-lipoxygenase; 5-LO), and are thus converted into one of four families of eicosanoids: the prostaglandins (PGs), prostacyclins, thromboxanes (TXs) and leukotrienes.

Eicosanoids have a short half-life, ranging from seconds to minutes. Their prime mode of action is mediated by binding to specific G protein-coupled receptors (GPCRs), many of which have been identified recently, enabling the rational development of specific receptor agonists and antagonists (see the accompanying Poster entitled 'Targeting lipid signalling in disease'). Eicosanoids can also bind to nuclear receptors. Eicosanoid signalling pathways are complex and are generally implicated in tissue homeostasis and/or inflammation. Prostanoids that are derived from $\omega-6$ unsaturated fatty acids, such as AA, tend to give rise to the production of inflammatory mediators, whereas $\omega-3$ unsaturated fatty acids are a source for anti-inflammatory and homeostatic prostanoids.

In addition, the lysolipids that are produced by the action of cPLA2 might themselves exert signalling functions and can be further processed: for example, when lysophosphatidylcholine (lyso-PC) is converted to platelet-activating factor (PAF, alkyl-acetyl phosphatidylcholine), which also supports inflammation. Anti-inflammatory drugs such as aspirin and other non-steroidal anti-inflammatory drugs (NSAIDs) function by blocking the cyclooxygenase-catalysed synthesis of prostanoids (prostacyclins, PGs and TXs) ${ }^{137,138}$.

are common to multiple lipid signalling pathways, resulting in the formation of highly interconnected lipid signalling networks. As a consequence, many lipid signalling pathways are deregulated in different disease conditions. This review attempts to integrate the role of lipid signalling networks in inflammation, cancer and metabolic syndrome. Owing to the focus on integration, an in-depth discussion of each individual lipid signalling pathway is beyond the scope of this review. We will also provide a brief overview of strategies that are currently being used to pharmacologically manipulate these lipid signalling networks. The commonality of various different signalling components means that different diseases share common points of intervention - this has important consequences for therapy, as will be discussed (see also the accompanying Poster entitled 'Targeting lipid signalling in disease'; URL in the box at the end of the article).

\section{Lipid signalling in inflammation}

Modulation of the levels and/or behaviour of lipids that are involved in promoting inflammation has been practised for centuries. Early records indicate that a brew of willow tree leaves was used by Hippocrates around $400 \mathrm{BC}$ to relieve pain and fever. Many centuries later, this led from the clinical use of aspirin (synthesized by Felix Hoffmann at Bayer in 1897) to the development of modern non-steroidal anti-inflammatory drugs (NSAIDs) and highly selective cyclooxygenase-2 (COX2) inhibitors. 
The biological versatility of phosphatidylinositol (Ptdlns) derives from its unique ability to be reversibly phosphorylated at three distinct positions of the inositol headgroup. Single or combinatorial phosphorylation of the 3,4 and 5 positions on the inositol ring of Ptdlns can generate at least seven unique phosphoinositides, which have diverse roles in receptor-mediated signal transduction, cytoskeletal remodelling, nuclear events and membrane trafficking. Lipid kinases, phosphatases and lipases that produce and degrade these signalling lipids spatially and temporally control the biological activity of phosphoinositides. Phosphoinositides signal through cytosolic effector proteins that have phosphoinositidebinding domains, which are frequently combined with additional modules that are involved in the formation of complex protein-protein and protein-lipid interaction networks ${ }^{7}$ (see the review by Lemmon in this issue).

The plasma-membrane-localized phosphatidylinositol4,5-bisphosphate (Ptdlns $(4,5) \mathrm{P}_{2}$ ) represents a focal point in phosphoinositide-dependent signalling because it serves as the substrate for two powerful receptor-regulated signal-generating enzymes (see figure). Cleavage of Ptdlns $(4,5) \mathrm{P}_{2}$ by phosphoinositide-specific phospholipase $\mathrm{C}$ (PLC) produces two second messengers, membraneassociated diacylglycerol (DAG) and the soluble inositol1,4,5-trisphosphate $\left(\operatorname{Ins}(1,4,5) \mathrm{P}_{3}\right)$ (see the review by Michell in this issue). Protein kinase $\mathrm{C}$ (PKC) docks through its $\mathrm{C} 1$ domain onto DAG, whereas $\operatorname{lns}(1,4,5) \mathrm{P}_{3}$ stimulates the release of $\mathrm{Ca}^{2+}$ ions from the endoplasmic reticulum (ER).

Alternatively, $\mathrm{Ptdlns}(4,5) \mathrm{P}_{2}$ can be converted to $\mathrm{Ptdlns}(3,4,5) \mathrm{P}_{3}$ by the class I phosphoinositide 3-kinases (PI3Ks). Ptdlns $(3,4,5) \mathrm{P}_{3}$ levels are negligible in resting cells, but can transiently and dramatically increase in response to growthfactor stimulation to mediate a wide variety of effects, including cell proliferation, migration, chemotaxis, phagocytosis and macropinocytosis, differentiation, survival and metabolic changes. Ptdlns $(3,4,5) \mathrm{P}_{3}$ functions by recruiting effectors that activate synergistic pathways. Prominent among these are guanine nucleotide-exchange factors and GTPaseactivating proteins, which regulate the actin cytoskeleton, and phosphoinositide-dependent protein kinase and protein kinase $B$ (PKB/Akt), which cooperate in the activation of important signalling cascades, such as the mammalian target of rapamycin (mTOR) pathway.

Ptdlns $(3,4,5) \mathrm{P}_{3}$ is dephosphorylated by two types of phosphatases: first, dephosphorylation at the 3 position by PTEN (phosphatase and tensin homologue deleted on chromosome ten) regenerates Ptdlns $(4,5) \mathrm{P}_{2}$ and is the 'off' signal. Second, dephosphorylation by 5-phosphatases such as SHIP1 and SHIP2 (Src-homology-2 (SH2) domain-containing inositol 5-phosphatase) generates Ptdlns $(3,4) \mathrm{P}_{2}$, which shares some actions with $\mathrm{Ptd}$ lns $(3,4,5) \mathrm{P}_{3}$ and can, for example, translocate PKB/Akt, but not Bruton's protein tyrosine kinase (Btk; see FIG. 2), to the plasma membrane. Polyphosphoinositides regulate a wide range of effector proteins that harbour PH, FYVE, PX and ENTH domains ${ }^{139}$ (see also the review by Lemmon in this issue). Ras-GRP, Ras guanyl nucleotide-releasing protein.

Players in inflammation. Chronic inflammation, autoimmunity and allergy arise from disturbances in vital host defence mechanisms. Lymphocytes detect antigens through T-cell and B-cell receptors (TCRs and BCRs), whereas immunoglobulin (Ig) receptors engage in neutrophil-dependent phagocytosis of foreign particles and in the activation of mast cells. Mast cells, macrophages and neutrophils can unleash irreversible tissue destruction. Independent of the cell type, immunoglobulin receptors (IgG receptors $(\mathrm{Fc} \gamma)$ in neutrophils and macrophages, IgE receptors (FceRI) in mast cells) couple to similar signal cascades that differ in the exact identity, but not functionality, of the protein kinases and adaptor proteins that are involved, and culminate in an increase in intracellular $\mathrm{Ca}^{2+}$ concentration $\left(\left[\mathrm{Ca}^{2+}\right]_{\mathrm{i}}\right)$.

In mast cells and granulocytes, elevated $\left[\mathrm{Ca}^{2+}\right]_{\mathrm{i}}$ initiates the release of granule contents and the formation of prostaglandins, thromboxanes and leukotrienes, which is followed by the production of cytokines and chemokines. Although leukocytes (lymphocytes, mast cells, granulocytes, macrophages and neutrophils) have common features of activation, the activation of mast cells will be discussed as a representative example because lipid signalling has been investigated extensively in these cells.

From antigen receptors to PtdIns $(4,5) \mathrm{P}_{2}$ turnover. Antigen-IgE complexes trigger the crosslinking of highaffinity IgE receptors and their association with lipid rafts on mast cells, initiating a cascade of protein tyrosine kinases. These phosphorylate immunoreceptor tyrosine-based activation motifs (ITAMs) on the cytosolic part of the IgE receptor and cause the translocation of the kinase Syk through its two Src-homology-2 (SH2) 


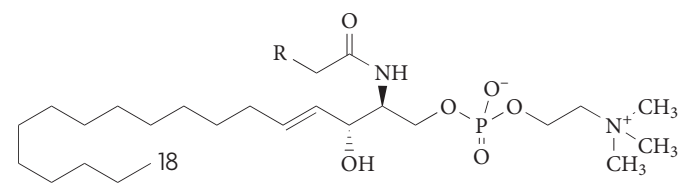

Sphingomyelin

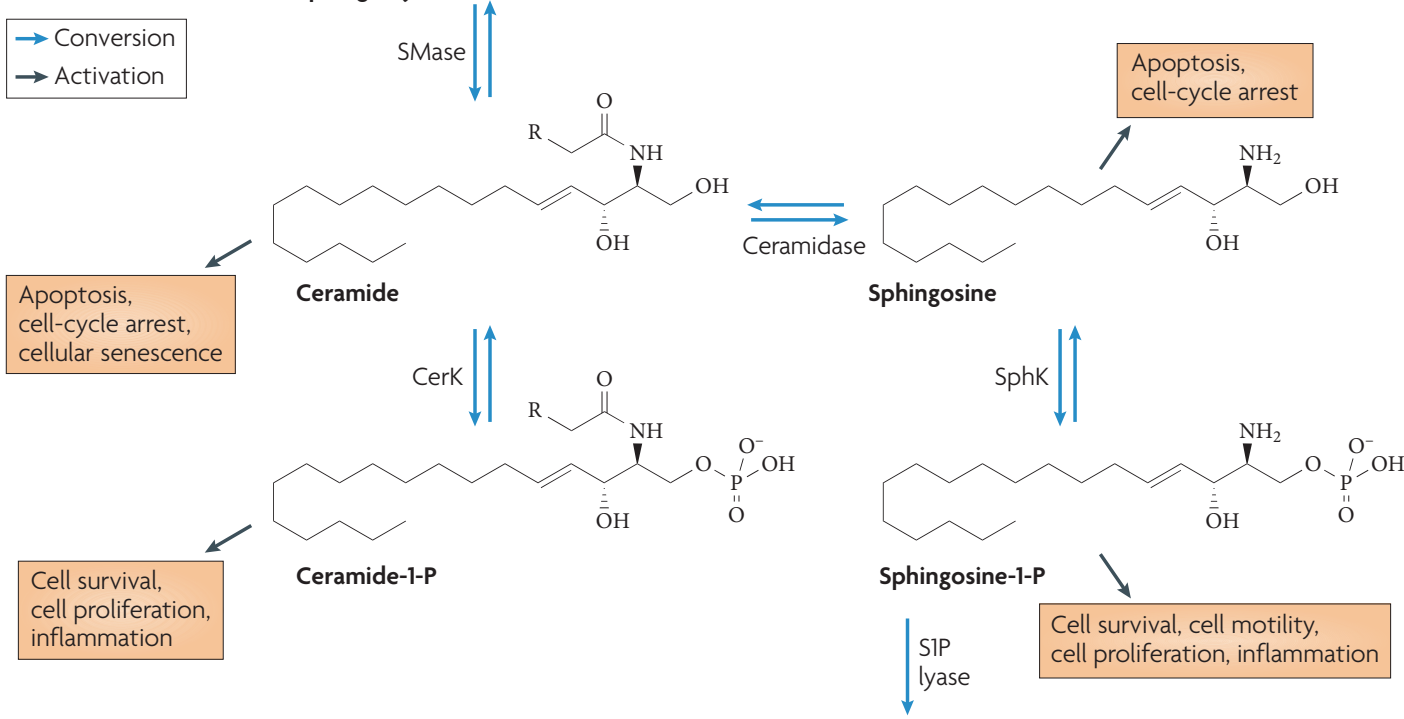

Degradation products

Sphingolipids are characterized by the presence of a particular aliphatic aminoalcohol, sphingosine (also termed a longchain base), instead of the glycerol that is found in glycerolipids. The turnover of sphingolipids can yield potent signalling molecules. Cleavage of sphingomyelin by sphingomyelinase (SMase) generates ceramide, which promotes apoptosis, cellcycle arrest and cellular senescence (see REFS 140,141 and the review by Hannun and Obeid in this issue). Ceramide can be phosphorylated by ceramide kinase (CerK) to form ceramide-1-phosphate (C1P), which has mitogenic properties, antagonizes the pro-apoptotic action of ceramide and promotes inflammation ${ }^{41}$. Alternatively, ceramide can be cleaved by ceramidase to produce sphingosine, which again mediates apoptosis and cell-cycle arrest. Sphingosine can, in analogy to ceramide, be phosphorylated by one of two sphingosine kinases (SphK1 or -2) to form sphingosine-1-phosphate (S1P). Sphingosine kinases thus form a crucial part of the 'sphingolipid rheostat' to balance the pro-apoptotic actions of ceramide with the pro-survival action of S1P (see figure). S1P operates both intracellularly and extracellularly to function in cell survival, cell motility, cell proliferation and inflammation. The extracellular actions of S1P are mediated by members of the lysophospholipid receptor family of G protein-coupled receptors (S1P1-5; previously known as the Edg family of receptors). The nature of intracellular S1P receptors is still controversial, and intracellular S1P actions are probably also linked to ceramide levels that are regulated through de novo synthesis ${ }^{142}$. S1P is degraded by S1P lyase to form ethanolamine phosphate and hexadecanal.

domains (see FIG. 2 and REF. 16). Further phosphorylation of membrane-anchored proteins (such as linker for activation of T cells (LAT) and non-T-cell activation linker (NTAL)) and soluble adaptor proteins (such as GAB2) starts a first wave of lipid signalling by recruitment of so-called class IA PI3K heterodimers that comprise the regulatory subunit $\mathrm{p} 85$ and catalytic subunit of PI3K $\left(\mathrm{PI} 3 \mathrm{~K}_{\mathrm{c}}\right)$ (FIG. 2).

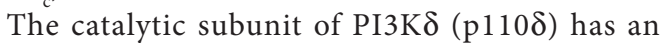
important role downstream of the IgE receptor ${ }^{17}$, but it also relays signals from the B-cell receptor and, to a lesser extent, the T-cell receptor ${ }^{18}$. Elevation of levels of $\operatorname{PtdIns}(3,4,5) \mathrm{P}_{3}$ by $\mathrm{PI} 3 \mathrm{~K}$ is crucial for the progression of antigen receptor signalling because the lipid recruits and activates proteins that contain pleckstrin homology $(\mathrm{PH})$ domains - among them, Bruton's tyrosine kinase (Btk) and PLC $\gamma$. Activation of PLC $\gamma$ through the generation of Ins $(1,4,5) \mathrm{P}_{3}$ causes $\mathrm{Ca}^{2+}$ release from internal stores. Usually, overstimulation of immune cells at low antigen concentrations is prevented by the $\mathrm{SH} 2$ domain-containing inositol 5-phosphatase-1 (SHIP1; for a review see REF. 19), which reduces the levels of $\operatorname{PtdIns}(3,4,5) \mathrm{P}_{3}$.

Through the second wave to the point of no return. If PtdIns $(3,4,5) \mathrm{P}_{3}$ levels remain high, phospholipase D (PLD) and sphingosine kinase ( $\underline{\text { SphK}}$ ) are activated, and release phosphatidic acid (PA) and S1P. S1P has been reported to act intracellularly on $\mathrm{Ca}^{2+}$ stores $^{20}$, but a distinct intracellular receptor has not been identified to date ${ }^{21}$. Once $\mathrm{Ca}^{2+}$ stores are emptied, they signal to open store-operated $\mathrm{Ca}^{2+}$ channels (SOCCs) in the plasma membrane and trigger a massive influx of extracellular $\mathrm{Ca}^{2+}$. This influx is required to initiate the activation of 
Some eicosanoids, as well as fatty acid derivatives and sterol derivatives, signal through nuclear hormone receptors, such as the farnesoid X receptor (FXR), liver X receptor (LXR) and peroxisome proliferator-activated receptors (PPARs). All of these lipid-sensing receptors heterodimerize with the retinoid $X$ receptor (RXR) to activate a feed-forward metabolic cascade that maintains nutrient lipid homeostasis by governing the transcription of a common family of genes involved in lipid metabolism, storage, transport and elimination ${ }^{78,143}$.

The PPARs $(\alpha, \gamma, \delta)$ were originally identified in Xenopus laevis as receptors that induce peroxisome formation. They are activated by polyunsaturated fatty acids, eicosanoids and various synthetic ligands. Consistent with the distinct expression pattern of these isoforms, gene-knockout experiments have revealed that each PPAR subtype carries out a specific function in fatty acid homeostasis. PPAR $\alpha$-regulated genes function together to coordinate the complex metabolic changes that are necessary to conserve energy during fasting and feeding. This isoform is the main target of fibrate drugs, a class of amphipathic carboxylic acids that are used in cholesterol disorders as an adjunct to statins, and in disorders that feature high levels of triglycerides. PPAR $\gamma$ was identified initially as a key regulator in adipogenesis, but it is also important in cellular differentiation, insulin sensitization, atherosclerosis and cancer. Ligands for PPAR $\gamma$ include fatty acids and other arachidonic acid metabolites, antidiabetic drugs and triterpenoids (polyisoprenes containing six isoprene units). In contrast to PPAR $\alpha$, PPAR $\gamma$ promotes fat storage by increasing adipocyte differentiation and the transcription of several important lipogenic genes. PPAR $\delta$ might affect lipid metabolism in peripheral tissue and its ligands include longchain fatty acids and carboprostacyclin. Hereditary disorders of all PPAR isoforms have been described and generally lead to a loss of function and concomitant lipodystrophy, insulin resistance and/or acanthosis nigricans ${ }^{144}$.

a plethora of $\mathrm{Ca}^{2+}$-sensitive signalling enzymes such as PKCs, ceramide kinase (CerK), cytosolic phospholipase A2 (cPLA2), 5-lipoxygenase (5-LO) and prostaglandin $\mathrm{H} 2$ synthase ( $\underline{\mathrm{PGH} 2 \mathrm{~S}})$, and to release histamine from mast cell granulae.

The activation of cPLA 2 by $\mathrm{Ca}^{2+}$-mediated translocation to the nuclear membrane is further supported by ceramide-1-phosphate (C1P; REF. 22), which is produced by CerK, and by the phosphorylation of cPLA 2 by multiple protein kinases ${ }^{23,24}$. Activated cPLA2 then releases arachidonic acid - the source of prostaglandins, leukotrienes and thromboxanes. These eicosanoids mediate the classical features of inflammation and promote a wide range of diseases from chronic inflammation, allergy, cardiovascular disease and obesity to cancer and more ${ }^{3,25}$. Eicosanoids ${ }^{26}$ and $\mathrm{S} \mathrm{P}^{11,27}$ act extracellularly through GPCRs, and function in conjunction with chemokines, cytokines and histamine. These inflammatory mediators promote bronchial constriction, increased vascular permeability and diameter, and the invasion of leukocytes, which, when in excess, cause tissue destruction in late allergy and inflammation ${ }^{19}$.

\section{Dysregulated lipid signalling in cancer}

In cancer that is derived from epithelial cells, early mutations increase cell growth and proliferation, which results in hyperplasia and adenoma. Malignant and fatal tumours develop when the cells can undergo contact-independent growth, become motile and cross the basal lamina to form metastases. Although tumour-cell-autonomous activation steps are important in cancer progression, signals derived from the tumour or stroma that influence, for example, endothelial cells (to mediate angiogenesis) and immune cells (for example, to avoid recognition and destruction) are equally crucial. Here, we provide a simplified overview of the intracellular and extracellular lipid-derived signals that function in tumour growth, and provide some insight into current attempts to modulate deviations in lipid synthesis in cancer (we will not cover other lipid-independent signal transduction pathways from the membrane to the nucleus ${ }^{28,29}$ ).
Phosphoinositides: from growth to metastasis. Many known oncogenes, such as mutated ERBB, insulin-like growth factor-1 (IGF1), c-Kit (stem-cell factor receptor), overexpressed chemokine receptors, mutated Ras, $\mathrm{BCR}-\mathrm{ABL}$ and elevated levels of the proto-oncogene Src, to name but a few, provide constitutive input signals to $\mathrm{PI} 3 \mathrm{~K}^{6,30}$. The finding that the 3-lipid phosphatase PTEN (phosphatase and tensin homologue deleted on chromosome ten) is frequently mutated in numerous late-stage tumours finally demonstrated that elevated levels of PtdIns $(3,4,5) \mathrm{P}_{3}$ contribute to oncogenesis ${ }^{31,32}$. PI3K $\alpha$ has also been found to be mutated in colon, gastric and breast cancer $^{33}$, and structural studies have recently elucidated how key mutations can constitutively activate the PI3K $\alpha$ complex by relieving the inhibitory action of the $\mathrm{p} 85$ regulatory subunit on the catalytic subunit $\mathrm{p} 110 \alpha^{34}$.

Of the numerous $\mathrm{PH}$-domain-containing proteins (see the review by Lemmon in this issue), protein kinase B ( $\underline{\mathrm{PKB}}$; also known as Akt) functions as an important node to relay signals from PI3K-generated PtdIns $(3,4,5) \mathrm{P}_{3}$ during growth and proliferation (FIG. 3; for reviews see REFS 35,36). PKB/Akt is upregulated or mutated in some tumours, and a mutation in the phosphoinositide-binding domain of PKB $\alpha /$ Akt1 that causes it to associate with the plasma membrane and renders it constitutively active has been identified ${ }^{37}$. PKB/Akt increases transcription and translation through the tuberous sclerosis complex (TSC), the target of rapamycin (TOR) complex-1 (TORC1; REF. 38) and phosphorylation of glycogen synthase kinase-3 $\beta$ (GSK3 $\beta$ ). PKB/Akt-controlled regulation of cyclin $\mathrm{D} 1$ and class $\mathrm{O}$ forkhead box (FOXO) transcription factors promotes cell-cycle entry, whereas $\mathrm{PKB} /$ Akt counteracts apoptosis through phosphorylation of the inhibitor of nuclear factor- $\kappa \mathrm{B}(\mathrm{I} \kappa \mathrm{B})$ kinase (IKK), caspase- 9 and the pro-apoptotic factor BAD. Elevation of $\operatorname{PtdIns}(3,4,5) \mathrm{P}_{3}$ levels also promotes the transition to malignancy, as several guanine nucleotideexchange factors for Rho GTPases - for example, Vav and Tiam - are directed to the membrane by PH domains. The cytoskeletal rearrangements that are subsequently stimulated enhance cell migration and metastasis ${ }^{39}$. 
Sphingolipids modulate growth and survival. Ceramide concentrations increase in response to cellular stress, such as DNA damage, disruption of lysosomal compartments or exposure to apoptotic stimuli. Although ceramide can be synthesized de novo, it is rapidly produced from sphingomyelin by the stress-induced activation of neutral sphingomyelinase (nSMase) and acid sphingomyelinase (aSMase) (BOX 3), which occurs rapidly and can lead to apoptosis. Ceramide can promote the clustering of death receptors ${ }^{40}$ and interferes with the relay of PI3K signals by activating protein phosphatases, such as ceramide-activated protein phosphatase (CAPP) (FIG. 3). Depending on the cell type and setting, however, ceramide can also mediate cell differentiation, cell-cycle arrest, apoptosis and senescence ${ }^{41}$, or it can be hydrolysed by ceramidase to yield sphingosine.

Sphingolipid metabolites have been recognized as important modulators of cell survival, cell growth, migration and angiogenesis, and therefore have an important role in cancer progression. Sphingosine has pleiotropic actions, including the ability to attenuate signalling by integrins and mitogen-activated protein kinase (MAPK). A truncated form of PKC $\delta$ has been described as a sphingosine-dependent protein kinase (SDK1). Substrates of SDK1 include 14-3-3 proteins; phosphorylated 14-3-3 proteins are reported to form dimers, which masks their binding sites and renders them unable to bind to phosphorylated targets ${ }^{42}$. For example, $\mathrm{BAD}$ is phosphorylated by $\mathrm{PKB} / \mathrm{Akt}$, and is subsequently retained in the cytosol where it is inactivated by 14-3-3 proteins. When 14-3-3 proteins are phosphorylated, they dimerize and release $\mathrm{BAD}$, which permeabilizes the outer mitochondrial membranes (reviewed in REF. 8). From this, it becomes clear that binding of 14-3-3 proteins to phosphorylated $\mathrm{PKB} /$ Akt substrates and SDK1 action on 14-3-3 proteins provide an intersection at which increased sphingosine intercepts with a branch of PI3K signalling.

Ceramide and sphingosine are mostly antiproliferative or pro-apoptotic, but they can be reversibly converted, respectively, to C1P by CerK and to S1P by SphK. $\mathrm{C} 1 \mathrm{P}$ and S1P both promote growth and counteract apoptotic stimuli (FIG. 3). C1P positively affects signalling by $\mathrm{PKB} / \mathrm{Akt}, \mathrm{PKA}$ and $\mathrm{PKC \zeta}$. C1P-mediated phosphorylation of $\mathrm{PKB} / \mathrm{Akt}$ was reported to be sensitive to PI3K inhibitors, which places C1P upstream of PI3K ${ }^{43}$. The ceramide-C1P and sphingosine-S1P balance thus exerts control on $\mathrm{PKB} / \mathrm{Akt}$ signalling upstream of PI3K and downstream of $\mathrm{PKB} / \mathrm{Akt}$ (through 14-3-3 protein dimerization). At the same time, PI3K can operate upstream of SphK, as demonstrated in mast cells (FIG. 2). It is therefore likely that the sphingolipid and phosphoinositide conversions are linked and cooperate to decide over the life or death of a cell.

\section{Lipid signalling in metabolic syndrome}

Lipid signalling is key for the aetiology of inflammation and cancer, but it also occupies a central role in the progression of the metabolic syndrome. The metabolic syndrome is a combination of medical disorders, which are probably triggered by high-calorie diets and

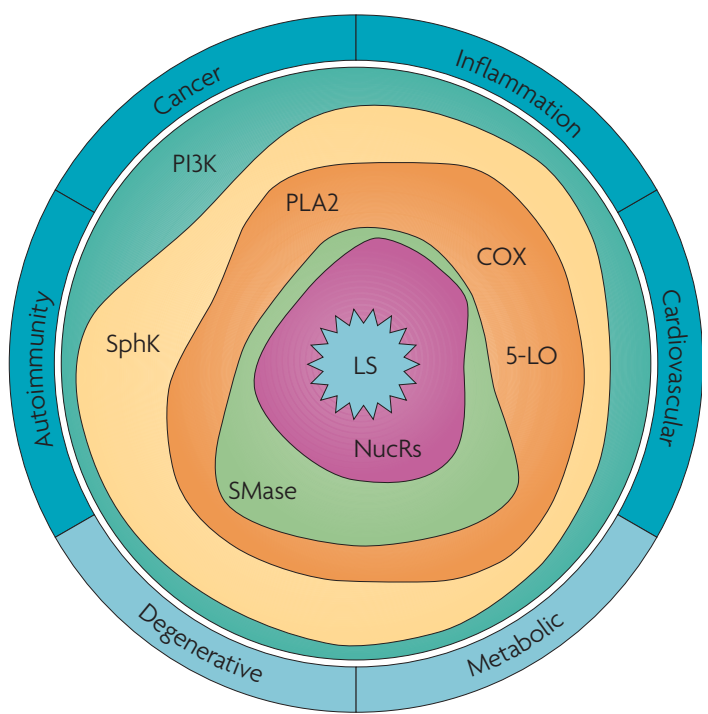

Figure 1 | Mounting walls. Lipid signalling (LS) is altered in a multitude of disease states and can dysregulate cell function in the immune system to provoke chronic inflammation, autoimmune reactions and allergy, contribute to cardiovascular disease, or promote tumour growth. Reduced rates of lipid signalling are often detected in degenerative and metabolic disease. The consequences of derailed lipid signalling can be therapeutically approached by inhibitors of lipid-modifying enzymes or lipid effector proteins (for example, nuclear receptors (NucRs)). Here, the width of such a 'therapeutic wall' - the space covered by a given coloured section between the centre (LS) and a respective disease schematically indicates the power of protection that therapeutic inhibition of the marked lipid-modifying enzymes might provide. Indeed, drugs that target peroxisome proliferator-activated receptors (PPARs) or other NucRs, and enzymes involved in the generation of eicosanoids (phospholipase A2 (PLA2), cyclooxygenase (COX), 5-lipoxygenase (5-LO)), as well as sphingosine kinase (SphK), phosphatidylinositol 3-kinase (PI3K) signalling and sphingomyelinase (SMase) are currently developed or already on the market (see the accompanying Poster entitled 'Targeting lipid signalling in disease'). Numerous lipid-modifying strategies are currently under investigation, but little attention is attributed to the crossinteractions that occur in the lipid network. A better understanding of synergistic lipid actions might generate novel strategies for more effective treatment of the diseases outlined above.

physical inactivity, and result in an increased risk of developing cardiovascular disease and diabetes. The symptoms that accompany the metabolic syndrome include adipocyte proliferation, inflammation, cellular stress, increased production of reactive oxygen species (ROS) and insulin resistance (FIG. 4). Owing to the drastic increase of the incidence of obesity during recent decades, obesity and its associated disorders now constitute a serious health threat to western civilization ${ }^{44}$. Gaining a more detailed understanding of its aetiology is therefore important to identify potential points of intervention. 


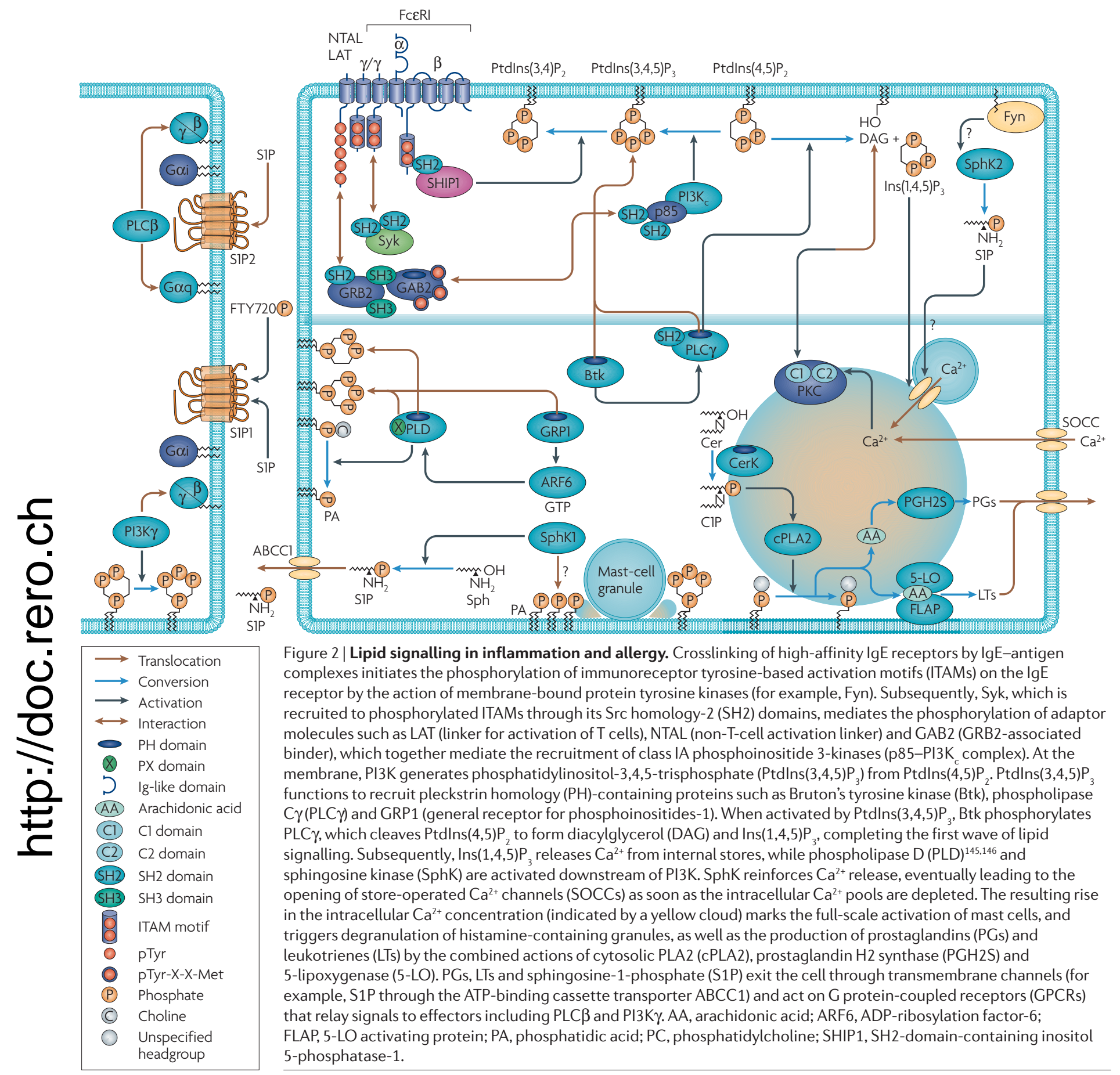

Insulin signalling. The insulin signalling pathway is central to the metabolic syndrome because obesity is often accompanied by insulin resistance and type 2 diabetes. Insulin and IGF receptors belong to the receptor protein tyrosine kinase family and, unlike other receptors in this family (which act through liganddependent dimerization and autophosphorylation), mainly catalyse tyrosine phosphorylation on docking proteins to mediate their signalling. Among other substrates, insulin stimulates tyrosine phosphorylation of insulin receptor substrate (IRS) ${ }^{45,46}$ proteins.
This mediates insulin action and is often attenuated in systemic insulin resistance, both in animal models and in human disease.

Under normal circumstances, IRS phosphorylation is linked to the activation of two main signalling pathways: first, the PI3K-PKB/Akt pathway, which is responsible for most of the metabolic actions of insulin, including uptake of glucose by the glucose transporter GLUT4 and glycogen synthesis; and second, the Ras-MAPK pathway, which cooperates with the PI3K pathway to control cell growth and differentiation. Control over insulin 


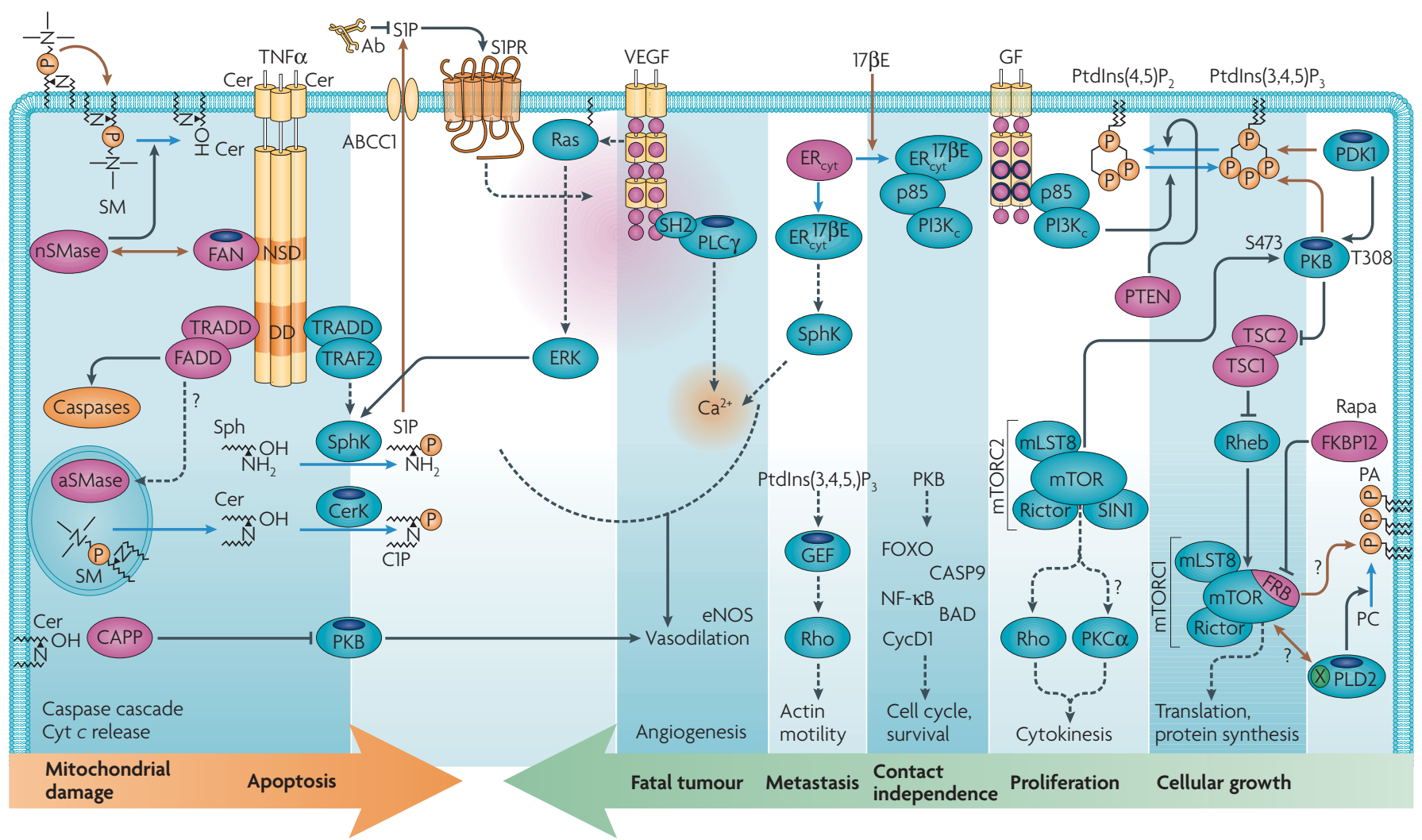

$\longrightarrow$ Translocation
$\longrightarrow$ Conversion
$\longrightarrow$ Activation
$\longrightarrow$ Inhibition
Interaction
P PH domain
PX domain
P PTyr
O PTyr-X-X-Met
SH2 SH2 domain
P Phosphate

Figure 3 | Pro- and anti-tumorigenic signals originate from membranes. Growth factor (GF) receptors, cytokine and chemokine receptors and oncogenes trigger several signalling pathways that contribute to cancer progression. Only input signals that trigger lipid-modifying or lipid-binding proteins are shown. Class IA phosphatidylinositol 3-kinases (shown as the p85-PI3K complex) can be activated by GF receptors directly, or by their phosphorylated substrates (not shown; for a review see REF. 5). Protein kinase B (PKB/Akt) is then translocated to PI3K-generated phosphatidylinositol3,4,5-trisphosphate (Ptdlns $(3,4,5) \mathrm{P}_{3}$ ) at the plasma membrane, where PKB/Akt is phosphorylated on Thr308 by phosphoinositide-dependent kinase-1 (PDK1) and on Ser473 by mammalian target of rapamycin complex-2 (mTORC2) to gain its full activity. Through the phosphorylation of TSC2 (tuberin) in the TSC2-TSC1 (hamartin) complex, PKB/Akt then releases the block on the GTPase Rheb to activate TORC1. TORC1 is a major relay to transcription and protein synthesis, and can be inhibited by the rapamycin (rapa)-FKBP12 complex. In cells that express the oestrogen receptor (ER ${ }_{\text {cyt }}$ ), the addition of an ER ligand (17 $\beta$-estradiol (17 $\beta E)$ ) has been reported to induce the formation of a PI3K-ER complex. Similarly, $17 \beta E$ was shown to induce sphingosine kinase (SphK) activity, which explains the cytosolic growth-promoting actions of ER. The vascular endothelial growth factor (VEGF)-induced activity of ERK can phosphorylate and activate SphK ${ }^{147}$, which generates sphingosine-1-phosphate (S1P). This is especially relevant in endothelial cells, in which S1P supports signalling by VEGF receptors. This process enforces a feed-forward loop that supports angiogenesis. Counteracting GF signalling, both ceramide (Cer) and sphingosine (Sph) can trigger pro-apoptotic events. Ceramide promotes the lateral association of death receptors that contain death domains (DD) and enforces, for example, TNF $\alpha$ receptor signalling to the caspase cascade. Through the neutral sphingomyelinase (nSMase) activating domain (NSD), the TNF $\alpha$ receptor augments the conversion of sphingomyelin (SM) to ceramide. At the same time, ceramide and sphingosine activate protein phosphatases (for example, ceramide-activated protein phosphatase (CAPP)), which attenuate PKB/Akt activation by the PI3K pathway. Whereas these processes promote apoptosis, the TNF $\alpha$ receptor also has a growth-promoting output towards SphK activation. ABCC1, ATP-binding cassette subfamily C member-1 transporter; C1P, ceramide-1-phosphate; CASP9, caspase-9; CerK, ceramide kinase; CycD1, cyclin D1; Cyt c, cytochrome c; ERK, extracellular signal-regulated kinase; FAN, factor associated with nSMase; FADD, Fas-associated death domain; FOXO, class O forkhead box transcription factor; NF- $\mathrm{KB}$, nuclear factor- $\mathrm{KB}$; PC, phosphatidylcholine; PLC, phospholipase C; TRADD, tumour necrosis factor receptor-associated death domain protein.

signalling is achieved by an autoregulatory feedback loop whereby the S6 kinase-1 (S6K1), a downstream effector of mTOR, inhibits upstream elements (a process known as homologous desensitization ${ }^{47,48}$ ). Alternatively, signals from apparently unrelated pathways can inhibit insulin signalling through heterologous desensitization to coordinate catabolic processes with, for example, cellular stress or tissue inflammation.
Lipids and insulin resistance. One of the key causes of metabolic syndrome is the constant oversupply of energy-rich nutrients - particularly fatty acids, but also carbohydrates and proteins or amino acids. Elevated plasma levels of fatty acids alone, however, are sufficient to induce insulin resistance and to activate a proinflammatory response ${ }^{49}$. The availability of free fatty acids is sensed by PPARs, which are nuclear receptors 
translocation of the Ptdins $(3,4,5) \mathrm{P}_{3}$-binding protein general receptor for phosphoinositides-1 (GRP1), which catalyses guanine nucleotide exchange on ADP-ribosylation factors (ARFs) and thereby interferes with the PI3K-dependent regulation of vesicular transport and membrane remodelling ${ }^{55}$. Ceramide therefore attenuates insulin signalling, and thereby contributes to insulin resistance, through multiple pathways.

Lipid accumulation induces cellular stress. The accumulation of excess lipid, in particular saturated fatty acids and sterols, might induce cellular damage through stress on the membranes of lipid-metabolizing organelles, especially the endoplasmic reticulum (ER) and possibly mitochondria ${ }^{56-58}$. Under these conditions, the ER activates a complex response system known as the unfolded protein response (UPR) to restore the functional integrity of the organelle ${ }^{59}$. Remarkably, orally active chemical chaperones that stabilize protein conformation and improve ER folding capacity can alleviate ER stress and can function as potent antidiabetic agents, restoring glucose homeostasis in mouse models of type 2 diabetes $^{60}$. The ER is also a major source of ROS and, consequently, oxidative stress $^{61,62}$. Oxidative stress is emerging as a feature of obesity and an important factor in the development of insulin resistance, and is frequently associated with mitochondrial dysfunction ${ }^{63-65}$.

Inflammation in metabolic syndrome. Lipid-derived signals, particularly eicosanoids and S1P, are important mediators of the inflammatory response. Inflammation itself, however, is a key feature of obesity and type 2 diabetes, as has become clear during the past decade ${ }^{66}$. Infiltration of adipose tissue by immune cells such as macrophages has recently been described in obese mice and humans ${ }^{67,68}$. Chronic inflammation is characterized by abnormal cytokine production ${ }^{69}$, and tumour necrosis factor- $\alpha$ (TNF $\alpha)$ has been found to be overexpressed in the adipose tissue of obese mice ${ }^{70}$. TNF $\alpha$ is a pro-inflammatory cytokine that activates various signal transduction cascades, including many of the pathways that are discussed below as crucial inhibitors of insulin action. In obese mouse models with a targeted mutation in the gene encoding TNF $\alpha$, insulin sensitivity and glucose homeostasis improved, which confirms that this inflammatory response has a vital role in the regulation of insulin action ${ }^{71,72}$. TNF $\alpha$ is also overexpressed in the adipose and muscle tissue of obese humans, and when exogenously administered, causes insulin resistance ${ }^{73}$.

Elevated plasma levels of free fatty acids can also directly elicit a pro-inflammatory response by binding to Toll-like receptors (TLRs). TLRs belong to a family of pattern-recognition receptors that are essential in the innate immune system for activating the nuclear factor- $\kappa \mathrm{B}(\mathrm{NF}-\kappa \mathrm{B})$-dependent pro-inflammatory signalling pathway in response to microbial pathogens or nutrients, particularly fatty acids ${ }^{74}$. Although TLR4 recognizes lipopolysaccharide from Gram-negative bacteria as a ligand, it is also activated by free fatty acids ${ }^{75}$.
Furthermore, mice that lack TLR4 are substantially protected from the ability of systemic lipid infusion to suppress insulin signalling in muscle and from insulinmediated changes in systemic glucose metabolism ${ }^{76}$.

Lipids coordinately regulate metabolic, innate immune and inflammatory processes ${ }^{77}$. Several transcription factors, particularly those of the PPAR and liver $\mathrm{X}$ receptor (LXR) families, seem to be crucial to integrate input from pathways involved in these processes. The ligands of all three PPAR family members suppress the production of pro-inflammatory cytokines, mostly by suppressing NF- $\kappa B^{14,78,79}$.

How obesity impinges on insulin signalling. Mounting evidence indicates that activation of c-Jun $\mathrm{N}$-terminal kinase (JNK), IKK and conventional PKC is central to the development of insulin resistance in response to obesity - mediated by the aforementioned fatty acidinduced ER stress, ROS production, TLR activation and inflammatory signalling by TNF $\alpha$. JNK, IKK and PKC have all been reported to inhibit insulin action by phosphorylating IRS1 on serine ${ }^{80-82}$. Serine phosphorylation of IRS1 disrupts insulin-receptor signalling through several distinct mechanisms and blocks insulin action $^{83,84}$.

JNK is activated after exposure to cytokines, such as TNF $\alpha$, as well as by free fatty acids through the TLR pathway and internal cues such as ER stress, all of which might underlie its obesity-induced activity ${ }^{60,80,85}$. There is a striking increase in JNK activity at crucial metabolic sites such as adipose and liver tissue in mouse models of obesity ${ }^{86}$. Most importantly, JNK deficiency protects mice from insulin resistance, fatty liver and diabetes ${ }^{86}$, which implies that JNK inhibition might be a promising therapeutic avenue for diabetes ${ }^{87-89}$.

Similarly, IKK is also activated through TLR4 and TNF $\alpha$. Mice that are heterozygous for a loss-of-function mutation in IKK $\beta$ are partly protected from obesityinduced insulin resistance, and inhibition of IKK $\beta$ by highdose salicylates improves insulin action in experimental models and humans ${ }^{90}$

$\mathrm{PKC}$ is the third important mediator between metabolic pathways and the inflammatory response $\mathrm{e}^{49,77,91}$. Fatty acid metabolites such as fatty acid coenzyme A and DAG can activate $\mathrm{PKC} \theta$ in muscles or PKC $\delta$ in the liver and inhibit insulin action ${ }^{49,77}$. Mice that are deficient in PKC $\theta$ are protected against fatty acid-induced insulin resistance, which confirms the contribution of this kinase to metabolic regulation in vivo ${ }^{91}$. At a mechanistic level, PKC $\theta$ is known to activate IKK and might contribute to insulin resistance through this pathway.

JNK, IKK and PKC also exert powerful effects on gene expression, including the promotion of inflammatory gene expression through the activation of activator protein-1 (AP-1) complexes and NF- $\mathrm{\kappa B}$. This activation results in downregulation of PPAR $\gamma$-dependent genes, possibly through competition for common activators, thus inhibiting adipocyte differentiation and clearing of circulating fatty acids ${ }^{92}$. Notably, JNK-AP-1 and IKKNF- $\kappa B$ are linked to components that sense and mediate ER stress and oxidative stress ${ }^{93-95}$. 
Taken together, free fatty acids seem to have a key role in inducing and mediating many of the symptoms that accompany the metabolic syndrome, including adipocyte proliferation, inflammation, cellular stress, increased ROS production and insulin resistance. A better characterization of the precise mechanisms by which these elevated levels of fatty acids result in the activation of key kinases such as JNK and PKC, and how they cause insulin resistance, will open new therapeutic opportunities to attenuate some of the pathologies and improve insulin responsiveness.

\section{Therapeutic opportunities}

Lipids in inflammation: points of interception. Strategies to attenuate chronic inflammation and allergy involve the interception of immune cell migration to target tissues and/or the blockage of signalling events, leading to the release of inflammatory mediators. $\mathrm{PI} 3 \mathrm{~K} \gamma$, the only class IB PI3K isoform, is activated by $\beta \gamma$ subunits of trimeric $G$ proteins that are dissociated by GPCRs to produce transient, but massive, elevations of PtdIns $(3,4,5) \mathrm{P}_{3}$. This lipid kinase integrates multiple signals from chemokines, complement fragments, formylated bacterial peptides and other stimuli, and was shown to be essential for chemokine-induced leukocyte migration in vivo ${ }^{96-98}$. Therefore, PI3K $\gamma$ has become the subject of impressive pharmacological efforts as a target to treat inflammatory disease $e^{5,99}$. PI3K $\gamma$ inhibitors (for example, AS605240) have shown therapeutic effects in mouse models of rheumatoid arthritis ${ }^{100}$ and systemic lupus erythematosus ${ }^{101}$, in which the compounds attenuated the migration of neutrophils and lymphocytes, respectively, into inflamed tissue.

As outlined above, the PI $3 \mathrm{~K} \delta$ isoform is activated downstream of a protein tyrosine cascade that emerges from Ig receptors. In the absence of PI3K $\delta$ activity - for example, in mice with a catalytically inactive $\mathrm{p} 110 \delta$ catalytic subunit ${ }^{17}$, or those treated with the PI3K $\delta$ inhibitor IC87114 (REF. 102) - degranulation of mast cells is attenuated. As a result, these mice are protected against the deleterious effects of IgE and allergen exposure. Histamine acts on endothelia to increase vascular permeability and dilation, causing a drop in body temperature and blood pressure, which can result in a fatal anaphylactic shock.

Surprisingly, elimination of the PI3K $\gamma$ isoform protects mice against IgE-allergen-mediated anaphylaxis, as described for the loss of PI3K $\delta$ activity above. PI3K $\gamma$ has not directly been linked to IgE-allergen-triggered clustering of FceRI, but the IgE-allergen causes the release of adenosine from mast cells, which signals through GPCRs to activate PI3K $\gamma$; the resulting peak in PtdIns $(3,4,5) \mathrm{P}_{3}$ is essential for the in vivo responsiveness of mast cells ${ }^{103}$. In addition, genetic evidence suggests that modulation of PI3K $\gamma$ activity could be beneficial in cardiovascular disease ${ }^{104}$, and dual PI $3 \mathrm{~K} \gamma / \delta$ inhibitors (for example, TG100-115) have entered clinical trials for myocardial infarction ${ }^{105}$. Owing to the above, PI3K $\gamma$ inhibitors have been enthusiastically dubbed the 'aspirin of the twenty-first century ${ }^{\prime 99}$, but single-specificity inhibitors for PI $3 \mathrm{~K} \gamma$ and $\mathrm{PI} 3 \mathrm{~K} \delta$ still await validation for the treatment of human disease.
By contrast, a high degree of validation and feasibility has been reached for targeting the sphingosine kinase pathway. FTY720 (fingolimod), when phosphorylated by sphingosine kinase, functions as an S1P receptor agonist and targets four (out of the five) S1P receptors. FTY720 interferes with the exit of lymphocytes from lymph nodes, and therefore attenuates autoimmune disease (for example, multiple sclerosis) ${ }^{106-108}$, organ rejection in transplantation, and is under consideration for other inflammatory and allergic conditions ${ }^{27,109}$. S1P1-specific agonists (SWE2871; REF. 110) and antagonists ${ }^{111}$ have helped to define S1P1 as the main target of S1P on lymphocytes. S1P1 antagonists also modulate endothelial permeability ${ }^{112}$, and thus also show some adverse effects.

Phospholipases A2, C and D have established roles in inflammation and allergy. Numerous efforts to target these enzymes have generated useful experimental inhibitors (see accompanying Poster 'Targeting lipid signalling in disease'), but no marketable drugs so far. Overall, PLA2 levels are modulated by corticosteroids ${ }^{113}$. Downstream of cPLA2, the cyclooxygenase (COX) activity of prostaglandin $\mathrm{H} 2$ synthase is a classic target of NSAIDs. Treatment of rheumatoid disease with the selective COX2 inhibitor rofecoxib (Vioxx) was associated with serious cardiovascular complications ${ }^{114}$, which raised fears that this result was coupled to COX2 as a drug target in general.

An alternative to inhibiting COX activity is targeting prostaglandin and thromboxane receptors. This inhibition has been achieved with ramatroban, marketed for allergic rhinitis, which blocks the TP receptor (this receptor binds thromboxane A2) and the chemoattractant receptor-homologous molecule that is expressed on Th2 lymphocytes (CRTH2; receptor for prostaglandin D2) in parallel ${ }^{115}$. Modulation of leukotriene action has also been shown to be effective against asthma and allergic rhinitis: zileton targets 5-LO with a limited potency, whereas montelukast, pranlukast and zafirlukast interfere with the action of cysteinyl leukotrienes (leukotrienes C4, D4 and E4) on cysteinyl leukotriene-1 and -2 receptors ${ }^{116,117}$.

It is evident, therefore, that modulation of extracellular and intracellular lipid signalling is beneficial in the treatment of inflammation, autoimmunity and allergy. Novel strategies are in progress; it seems that it is often not necessary to completely block the output of a given lipid pathway, but that partial attenuation of the lipid network is sufficient to generate a beneficial effect for the patient.

Targeting lipids in cancer. Presently, the PI3K pathway can be therapeutically targeted at the level of TORC1 by rapamycin (sirolimus and its derivatives temsirolimus and everolimus; FIG. 3). Tumours with constitutively elevated PtdIns $(3,4,5) \mathrm{P}_{3}$ (for example, owing to loss of PTEN or because of mutations in PI $3 \mathrm{~K} \alpha$ ) are especially sensitive to rapamycin ${ }^{118}$, but an important action of rapamycin-based drugs seems to be their effect on endothelial cells and angiogenesis ${ }^{38}$. Limited information is available concerning the in vivo isoform-specificity 
of novel PI3K inhibitors, and molecules with proven anti-tumour activity in xenograft models (PI-103 (REFS 119,120) and ZSTK474 (REF. 121)) are broadspectrum PI3K inhibitors, and might also owe some of their action to the inhibition of mammalian TOR (mTOR). NVP-BEZ235 has recently entered clinical trials as a treatment for solid tumours ${ }^{122}$. It is not clear whether or not targeting single PI3K isoforms will be successful in cancer therapy, and whether PI3K inhibitors will be effective as single agents. Collective data indicate that they will be of value in combination therapy: PI3K inhibitors have been shown to reverse resistance to trastuzumab (herceptin, a monoclonal antibody directed against ERBB2), which was caused by the loss of PTEN ${ }^{123}$.

As explained above, S1P is of major importance in the migration of lymphocytes out of secondary lymphatic organs. In cancer, S1P promotes cell growth and survival, angiogenesis, vascular maturation and mediates cell migration (FIG. 3). Using a monoclonal antibody with high affinity for S1P, Visentin and colleagues ${ }^{124}$ have demonstrated that providing a sink for S1P is sufficient to block angiogenesis and endothelial cell migration in response to vascular endothelial growth factor (VEGF) and basic fibroblast growth factor. The fact that the growth of an S1P-insensitive melanoma xenograft was inhibited indicates that removal of S1P hits a central signalling hub, which could prevent angiogenesis in various cancers (for an excellent comment see REF. 125). To further clarify the mechanism of action of $\mathrm{S} 1 \mathrm{P}$ removal, it would be interesting to compare the S1P antibodies with SphK inhibitors, which also have antiproliferative activity ${ }^{126}$, and are also expected to cause a build-up of intracellular sphingosine. An alternative strategy for lowering S1P levels might be the activation of S1P lyase ${ }^{127}$, an ER-localized enzyme, which cleaves S1P to yield ethanolamine phosphate and hexadecanal. Indeed, S1P lyase was reported to promote apoptosis and to be downregulated in colon cancer ${ }^{128}$.

An action that is independent of FTY720 phosphorylation was reported in chronic myelogenous leukaemia $(\mathrm{CML})$ cells, in which the fusion protein BCR-ABL drives proliferation: here, FTY720 triggered the activation of the protein phosphatase PP2A and, consequently, apoptosis ${ }^{129}$. Interestingly, PP2A regulates $\mathrm{PKCs}$ and $\mathrm{PKB} / \mathrm{Akt}$, providing another crossover point with PI3K signalling.

Sphingolipid and PI3K signalling not only control the same molecular targets, but the pathways also converge at the level of physiological responses. As an example, S1P (probably through S1P receptors ${ }^{130}$ ) and $\operatorname{PtdIns}(3,4,5) \mathrm{P}_{3}$ (through $\mathrm{PKB} / \mathrm{Akt}$ ) both lead to the activation of endothelial nitric oxide synthase (eNOS) and the release of nitric oxide (NO-) radicals. NO- acts through the NO-cyclic GMP pathway and, to some degree, through the formation of reactive nitrogen species to dilate blood vessels, decrease the bloodtumour barrier and to promote angiogenesis. This is clearly underlined by the lack of VEGF-induced angiogenesis in the absence of eNOS (reviewed in REF. 131). Based on the above, and on the fact that PI3K also acts downstream of the VEGF receptor, it becomes clear how PI3K inhibitors develop their anti-angiogenic activity $^{120}$.

Understanding the sphingolipid and polyphosphoinositide balance and their interconnection might therefore provide novel opportunities to achieve a stringent control of proliferation and growth of tumour cells and endothelia in angiogenesis, which is needed to interfere with the dissemination of adaptable and motile cancer cells.

Targeting metabolic syndrome. Given the complex aetiology of the metabolic syndrome, preventing the disease and its progression is a challenging task that must be addressed from various angles, preferably starting with the prevention of the intake of excess nutritional lipids to tame chronic inflammatory responses. Although a simple measure, it is often not applicable. Targeting the hormone-sensitive lipase (HSL), which liberates free fatty acids for cellular uptake, is an option that has been realized with the use of orlistat. Similarly, smallmolecule inhibitors of FABP4 have produced promising results in preventing metabolic syndrome in high-fat diet animal models, and raises hopes that this strategy might advance further ${ }^{50,52-54}$. Cellular stress that is caused by an excess of fatty acids can be alleviated using orally active chemical chaperones that act to stabilize protein conformation and improve the protein folding capacity of the ER. Such small molecular chaperones have indeed been proven to restore glucose homeostasis in preclinical models of type 2 diabetes ${ }^{60}$.

Nutrient overload also triggers alterations in gene expression, which are mediated by nuclear receptors as described above. Here, agonists for PPARs have a prototypic role, and rosiglitazone has been successfully used to manage insulin resistance. However, this treatment comes at a price because rosiglitazone is associated with an increased risk of myocardial infarction ${ }^{132}$.

Both the inflammatory branch of metabolic disease and insulin resistance can eventually be targeted by JNK. JNK deficiency has been reported to protect mice from insulin resistance, fatty liver and diabetes ${ }^{86}$, and inhibition of JNK is considered to be a promising therapeutic avenue ${ }^{87-89}$. Similarly, mouse models harbouring null mutations in IKK $\beta$ have validated that this kinase impacts insulin signalling, and inhibition of IKK $\beta$ by high-dose salicylates improves insulin action in experimental models and humans ${ }^{90}$.

Long-term complications in type 2 diabetes, such as diabetes-induced retinopathy, are the subject of clinical trials with PKC $\beta$ inhibitors (LY-333531; also known as ruboxistaurin $)^{133,134}$. It has also been claimed that PKC $\beta$ null mice - although they are hyperphagic - display an increased insulin sensitivity and fatty acid oxidation ${ }^{135}$. If applicable to humans, pharmacological manipulation of metabolic turnover could provide ways to lower visceral fat mass without reducing caloric intake. Whether this is desirable is, of course, another question, and maybe the best answer to this was given $\sim 200$ years ago by J. A. Brillet-Savarin: "Tell me what you eat, and I will tell you what you are”. 


\section{Conclusions and perspectives}

From the data presented above, it is clear that pathways that generate and respond to signalling lipids such as activation of PI3K, sphingolipid turnover, eicosanoid production and PPAR-dependent gene regulation have important roles in inflammation, cancer and metabolic syndrome. Lipid signalling events are shared among these different diseases; for example, metabolic syndrome involves inflammatory processes to develop into type 2 diabetes, atherosclerosis or cardiovascular disease; and cancer utilizes increased lipid signalling to progress from benign to malignant stages.

Lipid signalling cascades are complex, sometimes redundant and highly interconnected. Nevertheless, signalling lipid-generating enzymes have been and are still being targeted pharmacologically to alleviate the symptoms or even progression of the different diseases. In cases in which the modulation of one lipid signalling pathway does not suffice therapeutically, combinatorial treatments are being considered and may prove effective. Although such approaches can be explored experimentally in vivo or even clinically, the data to predict patient benefit are relatively scarce. This poor predictability of the in vivo response is, at least in part, caused by our incomplete understanding of the dominant and permissive properties of interacting lipid signalling pathways.
In addition, the tools that are available to follow the dynamics of agonist-modulated production of the lipid signal, to monitor the precise chemical modification of the lipid and its spatial organization are technically limited and hamper a more comprehensive description of these pathways and their interconnectivity. Unlike proteins, the function of which can largely be addressed individually, lipid actions are frequently masked by a large 'steady-state' mass represented by the structural lipids in the membrane, which makes it difficult to detect the transient lipid signal. Fluorescent probes - mostly based on lipid-binding protein domains such as $\mathrm{PH}$ domains - have been established for phosphoinositides ${ }^{136}$, but many of the other lipid mediators are still difficult to trace. Further advances in these fields and their integration for therapeutic use are, therefore, likely to benefit significantly from improved time-resolved methods to monitor lipid signals.

If this is achieved, we can substantiate what becomes apparent in this review: the lipid signalling pathways, studied in-depth in isolation elsewhere, do not operate independently, but mostly act in concert to control cell death, stasis or proliferation and cellular activity. Lipid signalling is context dependent and understanding the semantics of this molecular language is a challenge for the future.
1. Feldberg, W., Holden, H. F. \& Kellaway, C. H. The formation of lysocithin and of a muscle-stimulating substance by snake venoms. J. Physiol. 94, 232-248 (1938)

2. von Euler, U. S. On the specific vaso-dilating and plain muscle stimulating substances from accessory genital glands in man and certain animals (prostaglandin and vesiglandin). J. Physiol. 88, 213-234 (1936).

3. Boyce, J. A. Mast cells and eicosanoid mediators: a system of reciprocal paracrine and autocrine regulation. Immunol. Rev. 217, 168-185 (2007). Mackay, H. J. \& Twelves, C. J. Targeting the protein kinase $C$ family: are we there yet? Nature Rev. Cancer 7, 554-562 (2007)

5. Wymann, M. P., Zvelebil, M. \& Laffargue, M. Phosphoinositide 3-kinase signalling - which way to target? Trends Pharmacol. Sci. 24, 366-376 (2003).

6. Engelman, J. A., Luo, J. $\&$ Cantley, L. C. The evolution of phosphatidylinositol 3-kinases as regulators of growth and metabolism. Nature Rev. Genet. 7 , 606-619 (2006).

7. Di Paolo, G. \& De Camilli, P. Phosphoinositides in cell regulation and membrane dynamics. Nature 443 , 651-657 (2006)

8. Taha, T. A., Mullen, T. D. \& Obeid, L. M. A house divided: ceramide, sphingosine, and sphingosine-1-phosphate in programmed cell death. Biochim. Biophys. Acta 1758, 2027-2036 (2006)

9. Futerman, A. H. \& Hannun, Y. A. The complex life of simple sphingolipids. EMBO Rep. 5, 777-782 (2004)

10. Rosen, H. \& Goetzl, E. J. Sphingosine 1-phosphate and its receptors: an autocrine and paracrine network Nature Rev. Immunol. 5, 560-570 (2005).

11. Cyster, J. G. Chemokines, sphingosine-1-phosphate, and cell migration in secondary lymphoid organs. Annu. Rev. Immunol. 23, 127-159 (2005).

12. Ishii, I., Fukushima, N., Ye, X. \& Chun, J. Lysophospholipid receptors: signaling and biology. Annu. Rev. Biochem. 73, 321-354 (2004).

13. Meyer zu Heringdorf, D. \& Jakobs, K. H. Lysophospholipid receptors: signalling, pharmacology and regulation by lysophospholipid metabolism. Biochim. Biophys. Acta 1768, 923-940 (2007).

14. Beaven, S. W. $\&$ Tontonoz, P. Nuclear receptors in lipid metabolism: targeting the heart of dyslipidemia. Annu. Rev. Med. 57, 313-329 (2006).

15. Semple, R. K., Chatterjee, V. K. \& O'Rahilly, S. PPAR $\gamma$ and human metabolic disease. J. Clin. Invest. 116 581-589 (2006)
16. Rivera, J. \& Gilfillan, A. M. Molecular regulation of mast cell activation. J. Allergy Clin. Immunol. 117 1214-1225; quiz 1226 (2006)

17. Ali, K. et al. Essential role for the p1108 phosphoinositide 3-kinase in the allergic response. Nature 431, 1007-1011 (2004).

Reports a role for PI3K $\delta$ in IgE-mediated mast cell activation and c-Kit signalling. Because mast cell differentiation requires full c-Kit function, PI3K exerts an effect on mast cell numbers in certain tissues.

18. Okkenhaug, K., Ali, K. \& Vanhaesebroeck, B. Antigen receptor signalling: a distinctive role for the p1108 isoform of PI3K. Trends Immunol. 28, 80-87 (2007).

19. Rivera, J. \& Olivera, A. Src family kinases and lipid mediators in control of allergic inflammation. Immunol. Rev. 217, 255-268 (2007)

20. Choi, O. H., Kim, J. H. \& Kinet, J. P. Calcium mobilization via sphingosine kinase in signalling by the FceRI antigen receptor. Nature 380, 634-636 (1996)

21. Young, K. W. \& Nahorski, S. R. Sphingosine 1-phosphate: $\mathrm{CCa}^{2+}$ release mediator in the balance. Cell Calcium 32, 335-341 (2002).

22. Subramanian, P. et al. Ceramide 1-phosphate acts as a positive allosteric activator of group IVA cytosolic phospholipase A2 $\alpha$ and enhances the interaction of the enzyme with phosphatidylcholine. J. Biol. Chem. 280, 17601-17607 (2005).

23. Chalfant, C. E. \& Spiegel, S. Sphingosine 1-phosphate and ceramide 1-phosphate: expanding roles in cell signaling. J. Cell Sci. 118, 4605-4612 (2005).

24. Ghosh, M., Tucker, D. E., Burchett, S. A. \& Leslie, C. C. Properties of the group IV phospholipase A2 family. Prog. Lipid Res. 45, 487-510 (2006).

25. Yedgar, S., Krimsky, M., Cohen, Y. \& Flower, R. J. Treatment of inflammatory diseases by selective eicosanoid inhibition: a double-edged sword? Trends Pharmacol. Sci. 28, 459-464 (2007).

26. Kostenis, E. A glance at G-protein-coupled receptors for lipid mediators: a growing receptor family with remarkably diverse ligands. Pharmacol. Ther. 102 243-257 (2004).

27 Brinkmann, V. Sphingosine 1-phosphate receptors in health and disease: Mechanistic insights from gene deletion studies and reverse pharmacology. Pharmacol. Ther. 115, 84-105 (2007)
28. Di Cristofano, A. \& Pandolfi, P. P. The multiple roles of PTEN in tumor suppression. Cell 100, 387-390 (2000).

29. Rossi, D. J. \& Weissman, I. L. Pten, tumorigenesis, and stem cell self-renewal. Cell 125, 229-231 (2006).

30. Wymann, M. P. \& Marone, R. Phosphoinositide 3-kinase in disease: timing, location, and scaffolding. Curr. Opin. Cell Biol. 17, 141-149 (2005).

31. Maehama, T. \& Dixon, J. E. The tumor suppressor PTEN/MMAC1, dephosphorylates the lipid second messenger, phosphatidylinositol 3,4,5-trisphosphate. J. Biol. Chem. 273, 13375-13378 (1998).

32. Ali, I. U., Schriml, L. M. \& Dean, M. Mutational spectra of PTEN/MMAC 1 gene: a tumor suppressor with lipid phosphatase activity. J. Natl Cancer Inst. 91 1922-1932 (1999).

33. Samuels, Y. et al. High frequency of mutations of the PIK3CA gene in human cancers. Science 304, 554 (2004)

Along with reference 37 , introduces the concept of constitutive activation of the PI3K pathway through mutations in $\mathrm{PI} 3 \mathrm{~K} \alpha$ or the $\mathrm{PH}$ domain of PKB/Akt in human tumours.

34. Miled, N. et al. Mechanism of two classes of cancer mutations in the phosphoinositide 3-kinase catalytic subunit. Science 317, 239-242 (2007). The co-crystallized fragments of the $\mathrm{p} 85$ regulatory and the p110 catalytic subunits of PI3K $\alpha$ reveal the mechanism for how mutations in PI3K $\alpha$ that occur in human tumors cause constitutive activation of the $\mathrm{p} 85-\mathrm{p} 110 \alpha$ heterodimer.

35. Brazil, D. P., Park, J. \& Hemmings, B. A. PKB binding proteins. Getting in on the Akt. Cell 111, 293-303 (2002).

36. Manning, B. D. \& Cantley, L. C. AKT/PKB signaling: navigating downstream. Cell 129, 1261-1274 (2007)

37. Carpten, J. D. et al. A transforming mutation in the pleckstrin homology domain of AKT 1 in cancer. Nature 448, 439-444 (2007).

References 33 and 37 introduce the concept of constitutive activation of the PI3K pathway through mutations in PI3K $\alpha$ or the PH domain of PKB/Akt in human tumours.

38. Guertin, D. A. \& Sabatini, D. M. Defining the role of mTOR in cancer. Cancer Cell 12, 9-22 (2007).

39. Fritz, G. \& Kaina, B. Rho GTPases: promising cellular targets for novel anticancer drugs. Curr. Cancer Drug Targets. 6, 1-14 (2006). 
40. Miyaji, M. et al. Role of membrane sphingomyelin and ceramide in platform formation for Fas-mediated apoptosis. J. Exp. Med. 202, 249-259 (2005)

41. Gomez-Munoz, A. Ceramide 1-phosphate/ceramide, a switch between life and death. Biochim. Biophys. Acta 1758, 2049-2056 (2006).

42. Suzuki, E., Handa, K., Toledo, M. S. \& Hakomori, S. Sphingosine-dependent apoptosis: a unified concept based on multiple mechanisms operating in concert. Proc. Natl Acad. Sci. USA 101, 14788-14793 (2004).

43. Gomez-Munoz, A. et al. Ceramide-1-phosphate promotes cell survival through activation of the phosphatidylinositol 3-kinase/protein kinase B pathway. FEBS Lett. 579, 3744-3750 (2005).

44. Semenkovich, C. F. Insulin resistance and atherosclerosis. J. Clin. Invest. 116, 1813-1822 (2006).

45. Taniguchi, C. M., Emanuelli, B. \& Kahn, C. R. Critical nodes in signalling pathways: insights into insulin action. Nature Rev. Mol. Cell. Biol. 7, 85-96 (2006).

46. White, M. F. IRS proteins and the common path to diabetes. Am. J. Physiol. Endocrinol. Metab. 283, E413-E422 (2002)

47. Um, S. H. et al. Absence of S6K 1 protects against ageand diet-induced obesity while enhancing insulin sensitivity. Nature 431, 200-205 (2004).

Mice that are deficient in S6 kinase-1, an effector of the mammalian target of rapamycin (mTOR), are protected against obesity owing to enhanced $\beta$-oxidation. On a high-fat diet, these mice remain insulin sensitive owing to the loss of feedback inhibition of IRS by S6K 1 .

48. Um, S. H., D'Alessio, D. \& Thomas, G. Nutrient overload, insulin resistance, and ribosomal protein $\mathrm{S} 6$ kinase 1, S6K1. Cell Metab. 3, 393-402 (2006).

49. Boden, G. et al. Free fatty acids produce insulin resistance and activate the proinflammatory nuclear factor- $\mathrm{\kappa B}$ pathway in rat liver. Diabetes $\mathbf{5 4}$ 3458-3465 (2005).

50. Makowski, L et al. Lack of macrophage fatty-acid-binding protein aP2 protects mice deficient in apolipoprotein $\mathrm{E}$ against atherosclerosis. Nature Med. 7, 699-705 (2001)

51. Rosen, E. D. \& Spiegelman, B. M. PPAR $\gamma$ : a nuclear regulator of metabolism, differentiation, and cell growth. J. Biol. Chem. 276, 37731-37734 (2001)

52. Hotamisligil, G. S. et al. Uncoupling of obesity from insulin resistance through a targeted mutation in $\mathrm{PP} 2$ the adipocyte fatty acid binding protein. Science $\mathbf{2 7 4}$ 1377-1379 (1996)

53. Maeda, K. et al. Adipocyte/macrophage fatty acid binding proteins control integrated metabolic responses in obesity and diabetes. Cell Metab. 1 107-119 (2005)

54 Furuhashi, $M$ et al. Treatment of diabetes and atherosclerosis by inhibiting fatty-acid-binding protein aP2. Nature 447, 959-965 (2007) Describes an orally active small-molecule inhibitor of FABP4 as an effective therapeutic agent against severe atherosclerosis and type 2 diabetes in mouse models. These results suggest that FABP4 inhibitors may represent a new class of powerful therapeutic agents to prevent and treat metabolic diseases.

55. Summers, S. A. Ceramides in insulin resistance and lipotoxicity. Prog. Lipid Res. 45, 42-72 (2006).

56. Wei, Y., Wang, D., Topczewski, F. \& Pagliassotti, M. J. Saturated fatty acids induce endoplasmic reticulum stress and apoptosis independently of ceramide in liver cells. Am. J. Physiol. Endocrinol. Metab. 291, E275-E281 (2006)

57. Li, Y. et al. Enrichment of endoplasmic reticulum with cholesterol inhibits sarcoplasmic-endoplasmic reticulum calcium ATPase-2b activity in parallel with increased order of membrane lipids: implications for depletion of endoplasmic reticulum calcium stores and apoptosis in cholesterol-loaded macrophages. J. Biol. Chem. 279, 37030-37039 (2004).

58. Feng, B. et al. The endoplasmic reticulum is the site of cholesterol-induced cytotoxicity in macrophages. Nature Cell Biol. 5, 781-792 (2003).

59. Ron, D. \& Walter, P. Signal integration in the endoplasmic reticulum unfolded protein response Nature Rev. Mol. Cell. Biol. 8, 519-529 (2007).

60. Ozcan, U. et al. Chemical chaperones reduce ER stress and restore glucose homeostasis in a mouse model of type 2 diabetes. Science 313, 1137-1140 (2006). Together with reference 85 , shows that obesity causes ER stress, which in turn leads to hyperactivation of JNK, inhibitory phosphorylation of IRS and suppression of insulin receptor signalling. Chemical chaperones that enhance the adaptive capacity of the ER act as potent antidiabetic modalities with a potential application in the treatment of type 2 diabetes.

61. Cullinan, S. B. \& Diehl, J. A. Coordination of ER and oxidative stress signaling: the PERK/Nrf2 signaling pathway. Int. J. Biochem. Cell Biol. 38, 317-332 (2006)

62. Xue, X. et al. Tumor necrosis factor $\alpha$ (TNF $\alpha$ ) induces the unfolded protein response (UPR) in a reactive oxygen species (ROS)-dependent fashion, and the UPR counteracts ROS accumulation by TNF $\alpha$. J. Biol. Chem. 280, 33917-33925 (2005)

63. Furukawa, S. et al. Increased oxidative stress in obesity and its impact on metabolic syndrome. J. Clin. Invest. 114, 1752-1761 (2004).

64. Houstis, N., Rosen, E. D. ¿ Lander, E. S. Reactive oxygen species have a causal role in multiple forms of insulin resistance. Nature 440, 944-948 (2006). Indicates that antioxidants that lower ROS levels may be useful to treat type 2 diabetes and other insulin-resistant states.

65. Lowell, B. B. \& Shulman, G. I. Mitochondrial dysfunction and type 2 diabetes. Science 307 384-387 (2005).

66. Hotamisligil, G. S. Inflammation and metabolic disorders. Nature 444, 860-867 (2006).

67. Weisberg, S. P. et al. Obesity is associated with macrophage accumulation in adipose tissue. J. Clin. Invest. 112, 1796-1808 (2003).

68. Xu, H. et al. Chronic inflammation in fat plays a crucial role in the development of obesity-related insulin resistance. J. Clin. Invest. 112, 1821-1830 (2003).

69. Shoelson, S. E., Lee, J. \& Goldfine, A. B. Inflammation and insulin resistance. J. Clin. Invest. 116 1793-1801 (2006)

70. Hotamisligil, G. S., Shargill, N. S. \& Spiegelman, B. M. Adipose expression of tumor necrosis factor- $\alpha$ : direct role in obesity-linked insulin resistance. Science $\mathbf{2 5 9}$ 87-91 (1993).

71. Uysal, K. T., Wiesbrock, S. M., Marino, M. W. \& Hotamisligil, G. S. Protection from obesity-induced insulin resistance in mice lacking TNF- $\alpha$ function. Nature 389, 610-614 (1997).

72. Ventre, J. et al. Targeted disruption of the tumor necrosis factor- $\alpha$ gene: metabolic consequences in obese and nonobese mice. Diabetes 46, 1526-1531 (1997)

73. Krogh-Madsen, R., Plomgaard, P., Moller, K., Mittendorfer, B. \& Pedersen, B. K. Influence of TNF- $\alpha$ and IL- 6 infusions on insulin sensitivity and expression of IL-18 in humans. Am. J. Physiol. Endocrinol. Metab. 291, E108-E114 (2006)

74. Beutler, B. Innate immunity: an overview. Mol. Immunol. 40, 845-859 (2004).

75. Lee, J. Y., Sohn, K. H., Rhee, S. H. \& Hwang, D. Saturated fatty acids, but not unsaturated fatty acids, induce the expression of cyclooxygenase- 2 mediated through Toll-like receptor 4. J. Biol. Chem. 276 16683-16689 (2001)

76. Shi, H. et al. TLR4 links innate immunity and fatty acid-induced insulin resistance. J. Clin. Invest. 116 3015-3025 (2006)

77. Yu, C. et al. Mechanism by which fatty acids inhibit insulin activation of insulin receptor substrate-1 (IRS-1)-associated phosphatidylinositol 3-kinase activity in muscle. J. Biol. Chem. 277, 50230-50236 (2002)

78. Chawla, A., Repa, J. J., Evans, R. M. \& Mangelsdorf, D. J. Nuclear receptors and lipid physiology: opening the X-files. Science 294, 1866-1870 (2001).

79. Glass, C. K. \& Ogawa, S. Combinatorial roles of nuclear receptors in inflammation and immunity. Nature Rev. Immunol. 6, 44-55 (2006).

80. Aguirre, V., Uchida, T., Yenush, L., Davis, R. \& White, M. F. The c-Jun $\mathrm{NH}_{2}$-terminal kinase promotes insulin resistance during association with insulin receptor substrate-1 and phosphorylation of Ser(307). J. Biol. Chem. 275, 9047-9054 (2000).

81. Gao, Z. et al. Serine phosphorylation of insulin receptor substrate 1 by inhibitor $\mathrm{\kappa B}$ kinase complex. J. Biol. Chem. 277, 48115-48121 (2002)

82. Griffin, M. E. et al. Free fatty acid-induced insulin resistance is associated with activation of protein kinase $\mathrm{C} \theta$ and alterations in the insulin signaling cascade. Diabetes 48, 1270-1274 (1999).

83. Hotamisligil, G. S. et al. IRS-1-mediated inhibition of insulin receptor tyrosine kinase activity in TNF- $\alpha$ - and obesity-induced insulin resistance. Science 271, 665-668 (1996).
84. Zick, Y. Ser/Thr phosphorylation of IRS proteins: a molecular basis for insulin resistance. SCi. STKE 2005 pe4 (2005).

85. Ozcan, U. et al. Endoplasmic reticulum stress links obesity, insulin action, and type 2 diabetes. Science 306, 457-461 (2004).

Together with reference 60 , shows that obesity causes ER stress, which in turn leads to hyperactivation of JNK, inhibitory phosphorylation of IRS and suppression of insulin receptor signalling. Chemical chaperones that enhance the adaptive capacity of the ER act as potent antidiabetic modalities with a potential application in the treatment of type 2 diabetes.

86. Hirosumi, J. et al. A central role for JNK in obesity and insulin resistance. Nature 420,333-336 (2002).

87. Ricci, R. et al. Requirement of JNK2 for scavenger receptor A-mediated foam cell formation in atherogenesis. Science 306, 1558-1561 (2004).

88. Kaneto, H. et al. Possible novel therapy for diabetes with cell-permeable JNK-inhibitory peptide. Nature Med. 10, 1128-1132 (2004).

89. Liu, G. \& Rondinone, C. M. JNK: bridging the insulin signaling and inflammatory pathway. Curr. Opin. Investig. Drugs 6, 979-987 (2005).

90. Yuan, M. et al. Reversal of obesity- and diet-induced insulin resistance with salicylates or targeted disruption of IKK $\beta$. Science 293, 1673-1677 (2001).

91. Kim, J. K. et al. PKC- $\theta$ knockout mice are protected from fat-induced insulin resistance. J. Clin. Invest. 114 823-827 (2004)

92. Baud, V. \& Karin, M. Signal transduction by tumor necrosis factor and its relatives. Trends Cell Biol. 11 372-377 (2001)

93. Urano, F. et al. Coupling of stress in the ER to activation of JNK protein kinases by transmembrane protein kinase IRE1. Science 287, 664-666 (2000).

94. Deng, J. et al. Translational repression mediates activation of nuclear factor $\mathrm{\kappa B}$ by phosphorylated translation initiation factor 2. Mol. Cell. Biol. 24 10161-10168 (2004).

95. Hu, P., Han, Z., Couvillon, A. D., Kaufman, R. J. \& Exton, J. H. Autocrine tumor necrosis factor $\alpha$ links endoplasmic reticulum stress to the membrane death receptor pathway through IRE $1 \alpha$-mediated NF-kB activation and down-regulation of TRAF2 expression. Mol. Cell. Biol. 26, 3071-3084 (2006).

96. Hirsch, E. et al. Central role for $\mathrm{G}$ protein-coupled phosphoinositide 3-kinase $\gamma$ in inflammation. Science 287, 1049-1053 (2000)

97. Li, Z. et al. Roles of PLC- $\beta 2$ and $-\beta 3$ and PI3K $\gamma$ in chemoattractant-mediated signal transduction. Science 287, 1046-1049 (2000).

98. Sasaki, T. et al. Function of PI3K $\gamma$ in thymocyte development, $\mathrm{T}$ cell activation, and neutrophil migration. Science 287, 1040-1046 (2000)

99. Ruckle, T., Schwarz, M. K. \& Rommel, C. PI3K $\gamma$ inhibition: towards an 'aspirin of the 21 st century'? Nature Rev. Drug Discov. 5, 903-918 (2006).

100. Camps, M. et al. Blockade of PI3K $\gamma$ suppresses joint inflammation and damage in mouse models of rheumatoid arthritis. Nature Med. 11, 936-943 (2005).

101. Barber, D. F. et al. Class IB-phosphatidylinositol 3-kinase (PI3K) deficiency ameliorates IA-PI3K-induced systemic lupus but not T cell invasion J. Immunol. 176, 589-593 (2006). References 100 and 101 validated the pharmacological targeting of PI3K $\gamma$ to treat rheumatoid arthritis and lupus using preventive and semi-therapeutic protocols in mouse models.

102. Lee, K. S., Lee, H. K., Hayflick, J. S., Lee, Y. C. \& Puri, K. D. Inhibition of phosphoinositide 3-kinase $\delta$ attenuates allergic airway inflammation and hyperresponsiveness in murine asthma model. FASEB J. 20, 455-465 (2006).

103. Laffargue, M. et al. Phosphoinositide 3-kinase $\gamma$ is an essential amplifier of mast cell function. Immunity 16 441-451 (2002)

Shows that PI3K $\gamma$ has an essential role in IgEmediated mast cell activation and passive systemic anaphylaxis in vivo. IgE-antigen complexes initially trigger a weak activation of mast cells. This causes a release of adenosine, which acts in an autocrine or paracrine manner to activate trimeric $\mathrm{G}$ proteins and PI3K $\gamma$.

104. Patrucco, E. et al. PI3K $\gamma$ modulates the cardiac response to chronic pressure overload by distinct kinase-dependent and -independent effects. Cell 118 375-387 (2004) 
105. Doukas, J. et al. Phosphoinositide 3-kinase $\gamma / \delta$ inhibition limits infarct size after myocardial ischemia/ reperfusion injury. Proc. Natl Acad. Sci. USA 103, 19866-19871 (2006).

106. Kappos, L. et al. Oral fingolimod (FTY720) for relapsing multiple sclerosis. N. Engl. J. Med. 355 1124-1140 (2006).

107. Massberg, S. \& von Andrian, U. H. Fingolimod and sphingosine-1-phosphate - modifiers of lymphocyte migration. N. Engl. J. Med. 355, 1088-1091 (2006)

108. Miller, D. Multiple sclerosis: new insights and therapeutic progress. Lancet Neurol. 6, 5-6 (2007).

109 Baumruker, T., Billich, A. \& Brinkmann, V. FTY720, an immunomodulatory sphingolipid mimetic: translation of a novel mechanism into clinical benefit in multiple sclerosis. Expert Opin. Investig. Drugs 16, 283-289 (2007)

110. Wei, S. H. et al. Sphingosine 1-phosphate type 1 receptor agonism inhibits transendothelial migration of medullary T cells to lymphatic sinuses. Nature Immunol. 6, 1228-1235 (2005).

111. Sanna, M. G. et al. Enhancement of capillary leakage and restoration of lymphocyte egress by a chiral S1P antagonist in vivo. Nature Chem. Biol. 2, 434-441 (2006).

112. Rosen, H., Sanna, M. G., Cahalan, S. M. \& GonzalezCabrera, P. J. Tipping the gatekeeper: S1P regulation of endothelial barrier function. Trends Immunol. 28 102-107 (2007)

113. Reid, R. C. Inhibitors of secretory phospholipase A2 group IIA. Curr. Med. Chem. 12, 3011-3026 (2005).

114. Juni, P. et al. Risk of cardiovascular events and rofecoxib: cumulative meta-analysis. Lancet 364 , 2021-2029 (2004)

Reports on the withdrawal of the cyclooxygenase-2 inhibitor rofecoxib from the market owing to adverse cardiovascular effects.

115. Pettipher, R., Hansel, T. T. $\&$ Armer, R. Antagonism of the prostaglandin D2 receptors DP1 and CRTH2 as an approach to treat allergic diseases. Nature Rev. Drug Discov. 6, 313-325 (2007).

116. Steinke, J. W. \& Culp, J. A. Leukotriene synthesis inhibitors versus antagonists: the pros and cons. Curr. Allergy Asthma Rep. 7, 126-133 (2007).

117. Peters-Golden, M. \& Henderson, W. R. J. Leukotrienes. N. Engl. J. Med. 357, 1841-1854 (2007)

118. Neshat, M. S. et al. Enhanced sensitivity of PTENdeficient tumors to inhibition of FRAP/mTOR. Proc. Natl Acad. Sci. USA 98, 10314-10319 (2001).

119 Fan, O W. et al. A dual PI3 kinase/mTOR inhibitor reveals emergent efficacy in glioma. Cancer Cell 9 341-349 (2006)

120. Raynaud, F. I. et al. Pharmacologic characterization of a potent inhibitor of class I phosphatidylinositide 3-kinases. Cancer Res. 67, 5840-5850 (2007).

121. Yaguchi, S. et al. Antitumor activity of ZSTK474, a new phosphatidylinositol 3-kinase inhibitor. J. Natl Cancer Inst. 98, 545-556 (2006).

122. Stauffer, F. et al. Biochemical, cellular, and in vivo profiling of a new PI3K inhibitor from the imidazoquinoline series [abstract]. In American Association for Cancer Research Annual Meeting: Proceedings, 14-18 Apr 2007, Los Angeles, California. Abstract no. 269
123. Nagata, Y. et al. PTEN activation contributes to tumo inhibition by trastuzumab, and loss of PTEN predicts trastuzumab resistance in patients. Cancer Cell 6 , 117-127 (2004).

124. Visentin, B. et al. Validation of an anti-sphingosine-1phosphate antibody as a potential therapeutic in reducing growth, invasion, and angiogenesis in multiple tumor lineages. Cancer Cell 9, 225-238 (2006).

Highlights the therapeutic potential of anti-S1P antibodies in a mouse cancer model.

125. Milstien, S. \& Spiegel, S. Targeting sphingosine-1-phosphate: a novel avenue for cancer therapeutics. Cancer Cell 9, 148-150 (2006).

126. French, K. J. et al. Antitumor activity of sphingosine kinase inhibitors. J. Pharmacol. Exp. Ther. 318, 596-603 (2006).

127. Bandhuvula, P. \& Saba, J. D. Sphingosine-1phosphate lyase in immunity and cancer: silencing the siren. Trends Mol. Med. 13, 210-217 (2007).

128. Oskouian, B. et al. Sphingosine-1-phosphate lyase potentiates apoptosis via p53- and p38-dependent pathways and is down-regulated in colon cancer. Proc. Natl Acad. Sci. USA 103, 17384-17389 (2006).

129. Neviani, P. et al. FTY720, a new alternative for treating blast crisis chronic myelogenous leukemia and Philadelphia chromosome-positive acute lymphocytic leukemia. J. Clin. Invest. 117 2408-2421 (2007).

130. Skoura, A. et al. Essential role of sphingosine 1-phosphate receptor 2 in pathological angiogenesis of the mouse retina. J. Clin. Invest 117, 2506-2516 (2007).

131. Ying, L. \& Hofseth, L. J. An emerging role for endothelial nitric oxide synthase in chronic inflammation and cancer Cancer Res. 67 1407-1410 (2007).

132. Nissen, S. E. \& Wolski, K. Effect of rosiglitazone on the risk of myocardial infarction and death from cardiovascular causes. N. Engl. J. Med. 356 2457-2471 (2007).

133. Ishii, H. et al. Amelioration of vascular dysfunctions in diabetic rats by an oral PKC $\beta$ inhibitor. Science $\mathbf{2 7 2}$ 728-731 (1996).

134. Aiello, L. P. et al. Inhibition of PKC $\beta$ by oral administration of ruboxistaurin is well tolerated and ameliorates diabetes-induced retinal hemodynamic abnormalities in patients. Invest. Ophthalmol. Vis. SCi. 47, 86-92 (2006)

135. Bansode, R., Huang, W., Roy, S., Mehta, M. \& Mehta, K. D. Protein kinase $C$ deficiency increases fatty acid oxidation and reduces fat storage. J. Biol. Chem. 283, 231-236 (2008).

136. Balla, T. \& Varnai, P. Visualizing cellular phosphoinositide pools with GFP-fused proteinmodules. Sci. STKE 2002, pl3 (2002)

137. Funk, C. D. Prostaglandins and leukotrienes: advances in eicosanoid biology. Science 294, 1871-1875 (2001).

138. Serhan, C. N. Resolution phase of inflammation: novel endogenous anti-inflammatory and proresolving lipid mediators and pathways. Annu. Rev. Immunol. 25 , 101-137 (2007)

139. Cantley, L. C. The phosphoinositide 3-kinase pathway. Science 296, 1655-1657 (2002).
140. Clarke, C. J. \& Hannun, Y. A. Neutral sphingomyelinases and nSMase2: bridging the gaps. Biochim. Biophys. Acta 1758, 1893-1901 (2006).

141. Morales, A., Lee, H., Goni, F. M., Kolesnick, R. \& Fernandez-Checa, J. C. Sphingolipids and cell death. Apoptosis 12, 923-939 (2007).

142. Hait, N. C., Oskeritzian, C. A., Paugh, S. W., Milstien, S \& Spiegel, S. Sphingosine kinases, sphingosine 1-phosphate, apoptosis and diseases. Biochim. Biophys. Acta 1758, 2016-2026 (2006).

143. Mangelsdorf, D. J. et al. The nuclear receptor superfamily: the second decade. Cell $\mathbf{8 3}, 835-839$ (1995)

144. Berger, J. \& Moller, D. E. The mechanisms of action of PPARs. Annu. Rev. Med. 53, 409-435 (2002).

145. Morris, A. J. Regulation of phospholipase D activity, membrane targeting and intracellular trafficking by phosphoinositides. Biochem. Soc. Symp. 74 , 247-257 (2007)

146. Lee, J. S. et al. Phosphatidylinositol $(3,4,5)$ trisphosphate specifically interacts with the phox homology domain of phospholipase D1 and stimulates its activity. J. Cell Sci. 118, 4405-4413 (2005).

147. Pitson, S. M. et al. Phosphorylation-dependent translocation of sphingosine kinase to the plasma membrane drives its oncogenic signalling. J. Exp. Med. 201, 49-54 (2005).

\section{Acknowledgements}

We apologize for not citing many original publications due to space restrictions. We thank P. Fotiadou and R. Marone for corrections and discussions. M.P.W is supported by grants from Oncosuisse, the Krebsliga beider Basel, the Swiss National Science Foundation and the EU FP6 programme. R.S. is supported by grants from the Swiss National Science Foundation and Novartis Stiftung.

\section{DATABASES}

UniProtKB: http://beta.uniprot.org/uniprot 5-LO | aSMase $\mid$ CerK I COX2 I cPLA2 I nSMase $\mid$ PGH2S I PKB PLC |PLD|SphK

\section{FURTHER INFORMATION}

\section{Matthias P. Wymann's homepage:}

http://pages.unibas.ch/dbmw/biochemie

Roger Schneiter's homepage:

http://www.unifr.ch/biochem/default.php.

Genetics Home Reference: http://ghr.nlm.nih.gov

Mouse Genome Informatics: http://www.informatics.jax.org

Lysosomal Storage Diseases:

http://www.lysosomallearning.com

Clinical Trials: http://clinicaltrials.gov

Lipid Metabolites and Pathways Strategy:

www.lipidmaps.org

The Aspirin Foundation:

http://www.aspirin-foundation.com/

UCSD-Nature Signaling Gateway:

http://www.signalling-gateway.org/

DrugBank: http://redpoll.pharmacy.ualberta.ca/drugbank//

Novartis Oncology: Targeted Kinase Inhibitors - BEZ235

http://www.novartisoncology.com/page/bez235.jsp

\section{POSTER}

Targeting lipid signalling in disease: http://www.nature.

$\mathrm{com} / \mathrm{nrm} /$ posters/lipidsignalling-disease 